\title{
Can local fieldwork help to represent intra-urban variability of canopy parameters relevant for tropical African climate studies?
}

\author{
Jonas Van de Walle ${ }^{1}$ (D) Oscar Brousse ${ }^{1,2} \cdot$ Lien Arnalsteen $^{3}$. Disan Byarugaba ${ }^{3}$. Daniel S. Ddumba ${ }^{3}$. \\ Matthias Demuzere ${ }^{4,5}$. Shuaib Lwasa ${ }^{3}$. Gloria Nsangi ${ }^{6}$. Hakimu Sseviiri ${ }^{3}$. Wim Thiery ${ }^{7} \cdot$ Roxanne Vanhaeren $^{1}$. \\ Hendrik Wouters ${ }^{5,8} \cdot$ Nicole P.M. van Lipzig ${ }^{1}$
}

Received: 24 August 2020 / Accepted: 13 July 2021 / Published online: 13 August 2021

(C) The Author(s) 2021

\begin{abstract}
Rapid and uncontrolled urbanization in tropical Africa is increasingly leading to unprecedented socio-economical and environmental challenges in cities, particularly urban heat and climate change. The latter calls for a better representation of tropical African cities' properties relevant for urban climate studies. Here, we demonstrate the possibility of collecting urban canopy parameters during a field campaign in the boreal summer months of 2018 for deriving a Local Climate Zone (LCZ) map and for improving the physical representation of climate-relevant urban morphological, thermal and radiative characteristics. The comparison of the resulting field-derived LCZ map with an existing map obtained from the World Urban Data and Access Portal Tool framework shows large differences. In particular, our map results in more vegetated open low-rise classes. In addition, site-specific fieldwork-derived urban characteristics are compared against the LCZ universal parameters. The latter shows that our fieldwork adds important information to the universal parameters by more specifically considering the presence of corrugated metal in the city of Kampala. This material is a typical roofing material found in densely built environments and informal settlements. It leads to lower thermal emissivity but higher thermal conductivity and capacity of buildings. To illustrate the importance of site-specific urban parameters, the newly derived site-specific urban characteristics are used as input fields to an urban parametrization scheme embedded in the regional climate model COSMO-CLM. This implementations decreases the surface temperature bias from 5.34 to $3.97 \mathrm{~K}$. Based on our results, we recommend future research on tropical African cities to focus on a detailed representation of cities, with particular attention to impervious surface fraction and building materials.
\end{abstract}

Keywords Fieldwork · Tropical urban climate $\cdot$ Local climate zones · Urban canopy parameters · Urban climate modelling

\section{Introduction}

The rapid urbanization trend in Sub-Saharan Africa as seen in recent decades is expected to continue in the coming years due to increasing disparities between rural and urban environments, as well as climate change induced hazards, that force rural to urban migration (Barrios et al. 2006; Nawrotzki et al. 2017). Such fast and uncontrolled urban growth can lead to a very heterogeneous urban landscape with wealthy districts characterized by modern houses, big green gardens and asphalted roads, but also with informal

Jonas Van de Walle

jonas.vandewalle@kuleuven.be

Extended author information available on the last page of the article. settlements usually composed of densely built shacks made of corrugated metal sheets that are only accessible via small murrum alleys, typical unpaved but tamped roads (Vermeiren et al. 2012; Hemerijckx et al. 2020). In an observational study, Scott et al. (2017) demonstrated that such heterogeneous urban landscape results in intra-urban temperature variations in the city of Nairobi, Kenya, highlighting the presence of hotter air in informal settlements and suggesting heterogeneous hazards and vulnerability to urban heat in Sub-Saharan African cities.

The heat island effect of cities has been extensively studied worldwide, dating back to the early nineteenth century with pioneering studies by, e.g., Howard (1833), Renou (1868) and Hann (1885) (for a complete overview of classic urban heat island studies, see Stewart (2019)). Nevertheless, according to Stewart $(2011 \mathrm{a}, \mathrm{b})$, less than $5 \%$ of the 177 urban climate studies he reviewed focused on African 
cities-most likely due to the data scarcity in the region (Roth 2007; Acuto and Parnell 2016). Most of them were based on mobile or stationary in situ observations (Louw and Meyer 1965; Nakamura 1966; Gogh 1979; Okoola 1979; Okpara 2002; Jonsson et al. 2004; Offerle et al. 2005; Ndetto and Matzarakis 2013; 2015). Yet, the additional urban heat can affect (i) human health by increasing extreme heat and drought probability and by facilitating the transmission of some diseases (Frumkin 2002; Coccolo et al. 2016; Wouters et al. 2017); (ii) energy consumption, by increasing cooling demand and reducing heating needs (Martilli 2014; Santamouris et al. 2015; Ramon et al. 2020); and (iii) urban biodiversity (Beninde et al. 2015). Hence, more African urban climate studies are needed.

One of the first steps to be taken for coping with the regional data scarcity is to provide urban climate scientists with detailed urban canopy parameters (UCPs)_referring to parameters describing the urban characteristics between the surface and the highest roof level, typically varying at a local length scale of hundreds of meters to several kilometres (Oke et al. 2017). Such detailed UCPs are needed for a realistic representation of cities, which helps understanding the relations between the urban characteristics and the resulting urban climates (Stewart and Oke 2012). They are also required by urban climate models where they lead to an improved performance (Demuzere et al. 2017; Hammerberg et al. 2018; Ching et al. 2018; Varentsov et al. 2020). However, obtaining such detailed UCPs is a labour-intensive work that normally requires substantial technical and financial efforts Muller et al. (2013, 2015), Kamusoko (2017) and Ching et al. (2018). Information about building morphology, typology or materials is therefore rarely available for developing African cities, hence calling for cost-friendly and easily applicable data gathering methods (Acuto and Parnell 2016). Great effort has been made through the development of Local Climate Zones (LCZ) as a universal land use/cover classification for urban climate studies to provide a range of suitable UCPs for built and natural environments (Stewart and Oke 2012). The UCPs are not site-specific, but meant to be generally applicable to cities worldwide, having been sourced globally from in situ measurements, modelling studies, existing land-cover classifications, and urban climate literature reviews. Ultimately, the UCPs are placed into lookup tables for a variety of uses (e.g. Ching et al. 2018). However, for cities in Sub-Saharan Africa, and more particularly in Central and Eastern Africa, the representativity of these universal parameters remains unclear. Therefore, further investigation is needed to specify their values to the context of Central and Eastern Africa.

Brousse et al. $(2019,2020)$ already used these universal UCPs over the city of Kampala, Uganda. In particular, they demonstrated that recently developed open-source techniques can already provide morphological UCPs for the
TERRA_URB urban parametrization scheme embedded in the COSMO-CLM regional climate model (Rockel et al. 2008; Wouters et al. 2016). This was done by deriving spatially varying UCPs out of the LCZ map of Kampala (Brousse et al. 2019), following the World Urban Database and Access Portal Tools (WUDAPT) framework (Ching et al. 2018). But, as explained before, site-specific information might also be of added value for this East-African city. For example, site-specific morphological UCPs could be retrieved directly from remote sensing techniques, and climate-relevant radiative and thermal properties for a variety of building materials could be obtained using in situ, airborne or laboratory techniques (Herold et al. 2004; Nasarudin and Shafri 2011; Loridan and Grimmond 2012; Kotthaus et al. 2014). Yet, gathering site-specific information is best done by a visit to the field sites in person (Stewart and Oke 2012).

Therefore, the primary goal of this study is to compare universal UCPs with site-specific field-derived UCPs for the city of Kampala, taken as a case study. To this end, we describe the fieldwork methodology for efficiently gathering relevant parameters at low cost that best represent the urban heterogeneity in terms of morphology and building materials for urban climate studies. Moreover, we elaborate a framework for the extrapolation of the field data using LCZ, and show the possibility to upscale the field data to a grid at the kilometre scale. To test the applicability of our field data and upscaled fields, a climate model is run for the short dry season of 2017-2018 and (near-) surface temperatures are evaluated against remotely sensed and in situ observations.

\section{Methods}

The methodology is divided into four parts. First, the general procedure to derive universal UCPs is described, explaining both the WUDAPT initiative and the LCZ framework. Second, we describe the details of the fieldwork, resulting in a large dataset exceeding 1300 measuring points. Third, we explain how this data can be used (i) to obtain an alternative fieldwork-derived LCZ map and (ii) to derive site-specific UCP values. Fourth, we exemplify how to use this site-specific fieldwork-derived data for urban climate modelling.

\subsection{Procedure for universal urban canopy parameters}

The World Urban Database and Access Protal Tools (WUDAPT, Ching et al. (2018)) project is a community effort aiming at acquiring climate-relevant information on cities worldwide and developing tools to support climate 
research. An important part of the WUDAPT project relies on the use of the universal LCZ classification (Stewart and Oke 2012) that distinguishes typical urban landscapes that are known to have recognizable effects on and interactions with the local climates. Therefore, the LCZ classification is divided in 7 natural and 10 built classes (Stewart and Oke 2012) that offer universal ranges of parameters representing the urban environment in terms of impervious coverage, building density and height, anthropogenic heat fluxes and heat storage capacities. Former studies already demonstrated that the derivation of some UCPs through the WUDAPT framework are very helpful for urban climate modelling, though usually implementing morphological parameters only (e.g. Brousse et al. 2016, Alexander et al. 2016, Verdonck et al. 2017, Hammerberg et al. 2018, Wong et al. 2019, Zonato et al. 2020). This UCP derivation typically consists of associating the mean value of the universal ranges of Stewart and Oke (2012) to each built LCZ that is present in the city. These ranges were defined based on data gathered for cities worldwide (Stewart and Oke 2012). Yet, local climate work in tropical African cities could potentially benefit from additional measurements of site-specific UCPs.

The WUDAPT framework offers an innovative opensource method for mapping LCZ globally. Following this framework, the first step for obtaining an LCZ map consists of manually creating polygons in Google Earth that exemplify each LCZ type present in the selected domain. These polygons then serve as a training set for a random forest classifier-implemented in the SAGA software (Breiman 2001; Bechtel et al. 2015)—for mapping a predefined domain out of Landsat 8 images, possibly combined with other satellite sources retrieved from the Google Earth Engine (Gorelick et al. 2017). In addition, accuracy measures of the LCZ map are obtained by repeatedly creating the LCZ map with a random sample of $70 \%$ of the training data, while the remaining $30 \%$ is used for validation. This bootstrap procedure is repeated 25 times, ultimately providing accuracies per LCZ class as well as overall accuracy measures Bechtel et al. (2017, 2020). The LCZ mapping approach has been used to map Europe and the Continental United States Demuzere et al. (2019a, 2020) in the form of LCZ. Brousse et al. $(2019,2020)$ also applied this procedure for mapping the city of Kampala.

\subsection{Fieldwork}

The LCZ map and corresponding universal UCP values produced by this generic procedure will be compared to site-specific in situ measurements, to test how the latter can improve the physical representation of African cities. Therefore, a fieldwork exercise has been set up. In particular, for a well-considered sample of points, quantitative measurements of building heights and canyon widths are taken, and estimates are made by two independent observers for material fractions of roads, walls and roofs.

\subsubsection{Preparation}

Multiple locations within Kampala are selected for sampling the heterogeneous city during the field work, considering three main criteria. First, the LCZ map for Kampala from Brousse et al. (2019) is used as an initial guideline. The fraction of measuring points per LCZ is chosen proportional to the area fraction of the LCZ map, with approximately $1 \%$ compact mid-rise (LCZ 2), $17 \%$ compact low-rise (LCZ 3), 77\% open low-rise (LCZ 6), 3\% informal settlements (LCZ 7) and 2\% large low-rise (LCZ 8). Second, measuring points are selected along short transects crossing parts of the city, making the work logistically feasible. Third, the accessibility and safety of each of the mapped transects is approved by local guides. The total distance of each transect is aimed at 3 to $5 \mathrm{~km}$ and includes an observation every $120 \mathrm{~m}$. This length scale is a compromise between capturing the heterogeneity and maximizing the number of measurements per walkable distance, and follows the optimal horizontal resolution of $100 \mathrm{~m}$ proposed by Bechtel et al. (2015) for digital LCZ mapping. Transects are drawn in Google Earth (GE) and transferred to Basecamp software that allows uploading the route to a Global Positioning System (GPS) device. This resulted in a total sample of more than 1300 measurement locations across the city (Fig. 1, the raw data with the exact locations is freely available in Van de Walle et al. (2020a)).

\subsubsection{In the field}

Two teams are assembled to survey both sides of the street canyon. Each team consists of at least three members taking care of specific tasks. First, the straight transects on the GPS have to be followed as close as possible, taking either big roads or small alleys and avoiding dead ends. The actual transects are saved using the Locus smartphone application (Fig. 1). Second, at each stop the two closest buildings are selected at both sides of the street canyon. In theory, these two buildings should be representative of the local-scale environment. In practice, buildings can vary at much smaller scales and the predefined buildings at fixed distances can thus result in unrepresentative buildings. However, we can rely on the large sample of measurements to assume that the derived statistics do represent the variety within one LCZ environment. Several examples of such stop locations are shown together with images viewed from Google Earth (Fig. 2). When the buildings are selected, 


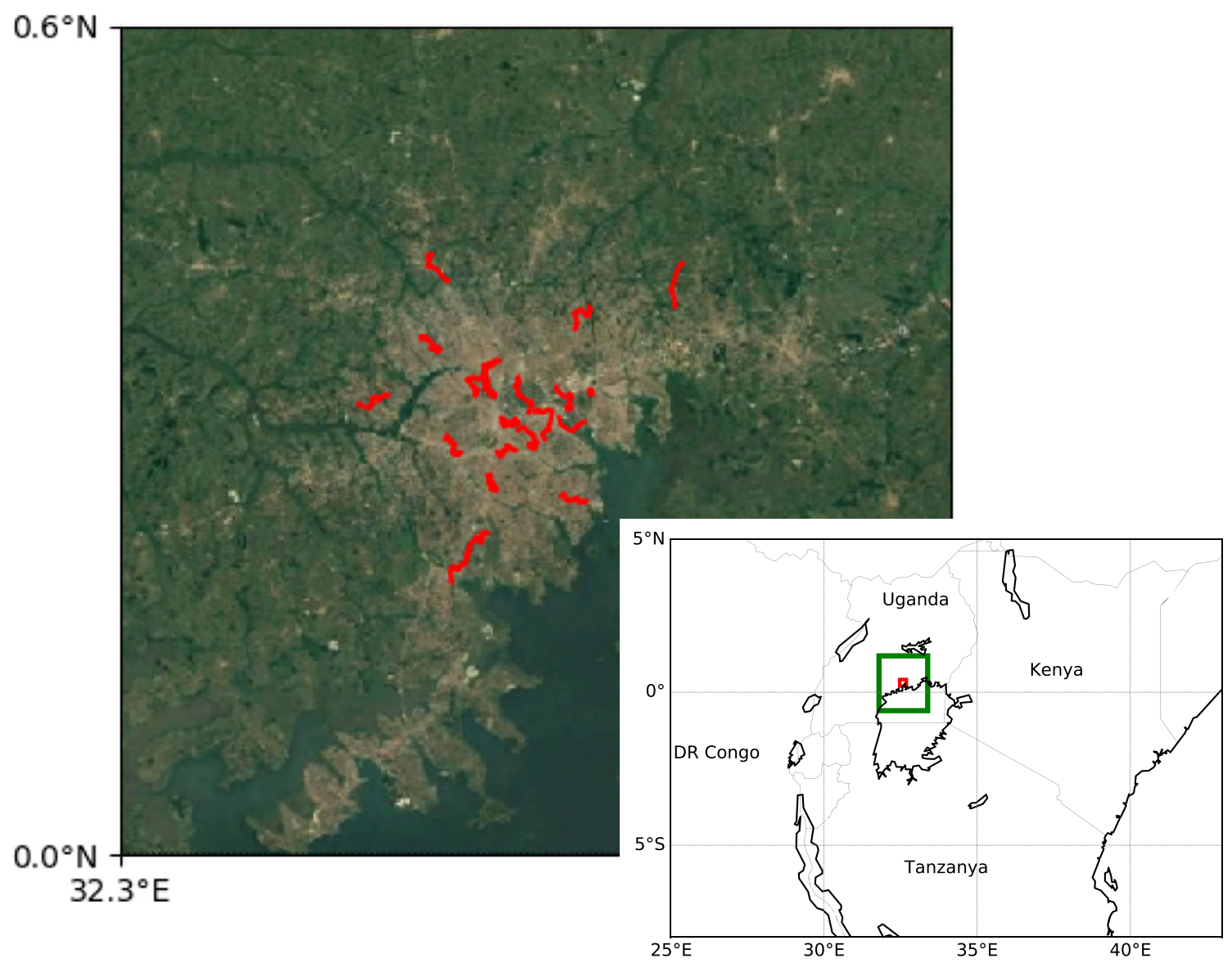

Fig. 1 Google Earth image of the evaluation domain, centred around the city of Kampala, Uganda, indicated by the red box on the inset figure, while the bigger green box presents the simulation domain of

quantitative measurements related to those buildings are obtained using a Nikon Forestry Pro laser distance meter. The measurements include building height, road width and distance from the road to the building, measured perpendicular to the road (Fig. 3). Road width and distances from the road to the building at both sides of the street canyon are summed to obtain the canyon width. Together with the stop location and timing, these measurements are entered in an Open Data Kit (ODK-Collect) smartphone application. Third, two independent observers make estimates for material fractions of the street, the wall and the roof of the two selected buildings. For simplicity, only three major material categories are considered for this study: asphalt, earthenware and metal. The asphalt group includes road asphalt, asphalted roofs and concrete walls. In the earthenware group, murrum roads as well as red bricks for walls and tiles for roofs are included, all originating from compressed earth. Corrugated metal is an important building material in Kampala, particularly for roofs. The resulting information from the estimations of both observers is collected in the the high-resolution regional climate model. The transects along which the measurements are gathered are indicated in red

ODK-Collect app, each specifying fractions for the parameters road_asphalt, road_murrum, wall_concrete, wall_brick, wall_metal, roof_asphalt, roof_tiles and roof_metal. Despite the fact that the estimates are prone to the observer's interpretation, the estimates of both independent observers are checked afterwards. For very different results (percentages off by more than $20 \%$ ), pictures are consulted if available to check for errors, possibly leading to the removal of the data at this location. For similar results, the mean of both estimates is computed. All collected information is schematically represented in Fig. 3 and online available (Van de Walle et al. 2020a).

\subsection{Processing the fieldwork data using local climate zones}

The fieldwork dataset includes morphological parameters and building material fractions for each of the 1312 measuring points. The use of this data is twofold. First, the LCZ map from Brousse et al. (2019) is upgraded by 
Fig. 2 Examples of some measuring locations in different LCZ environments throughout the city, seen from above (first column) and from eye height (second and third columns). The former image is obtained from Google Earth, with the observation location centred and the image edges set equal to $2 \mathrm{~km}$. The latter pictures are taken during the fieldwork, showing two buildings at each side of the road. They are labelled with their measurement date by day and month, followed by the measurement number and the side of the road (L/R) relative to our walking direction. This labelling is consistent with the raw dataset

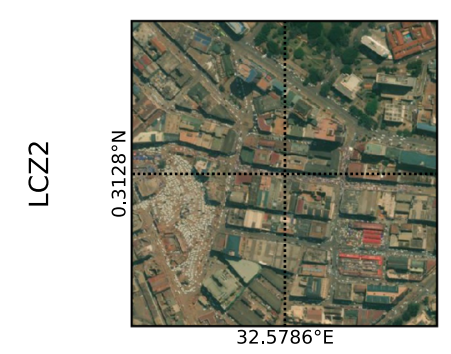

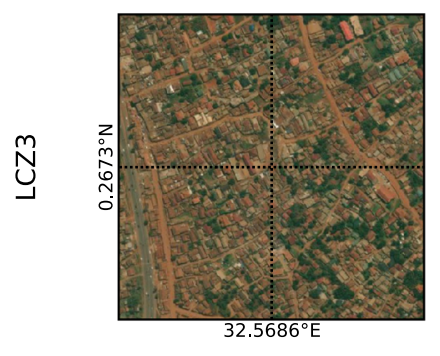

20/08_19L

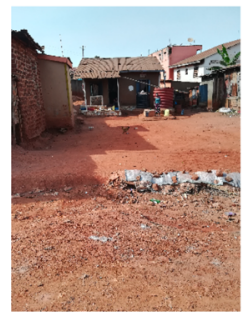

27/07_3R

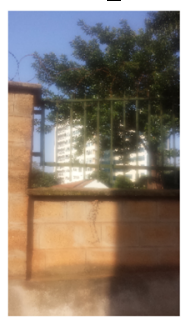

27/07_14R

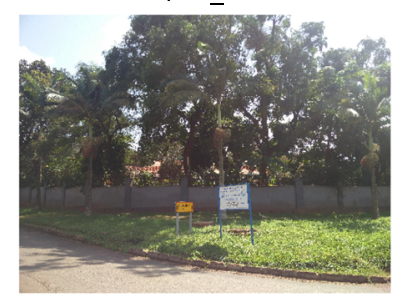

30/07_7R

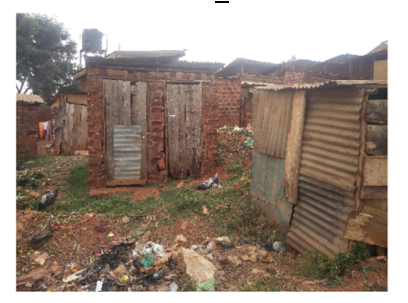

$31 / 078 R$
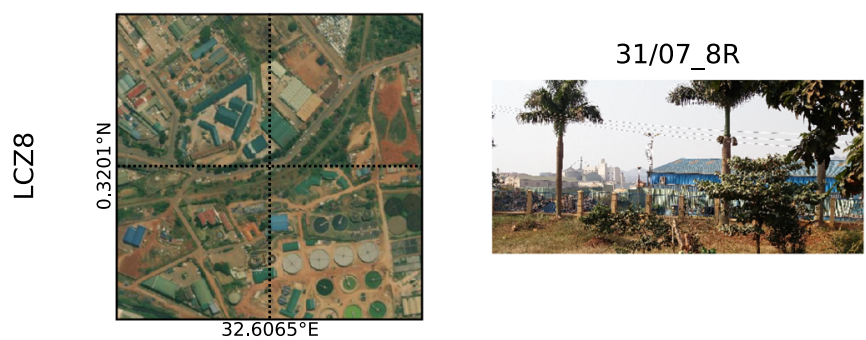

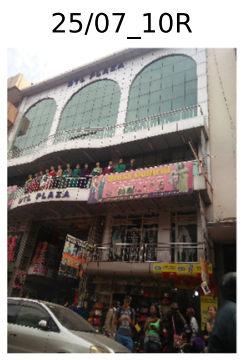

25/07_10L

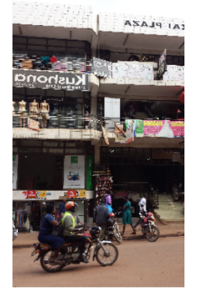

20/08_19R

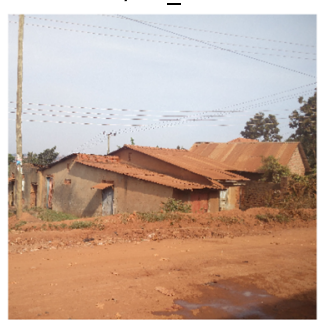

27/07_2L

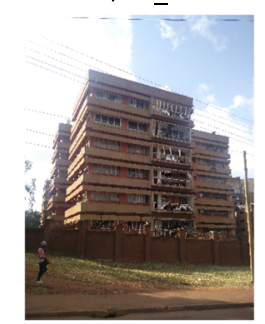

27/07_15R

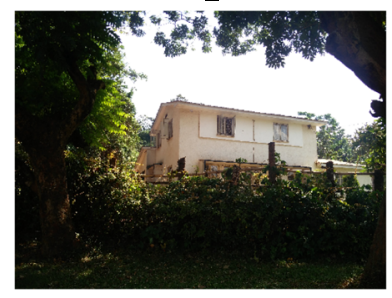

30/07_7L

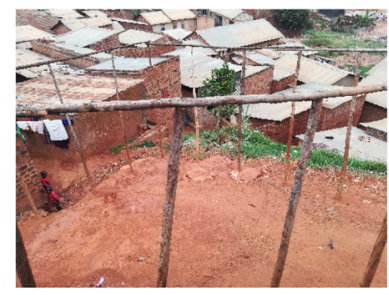

31/07_7L

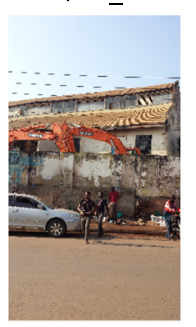




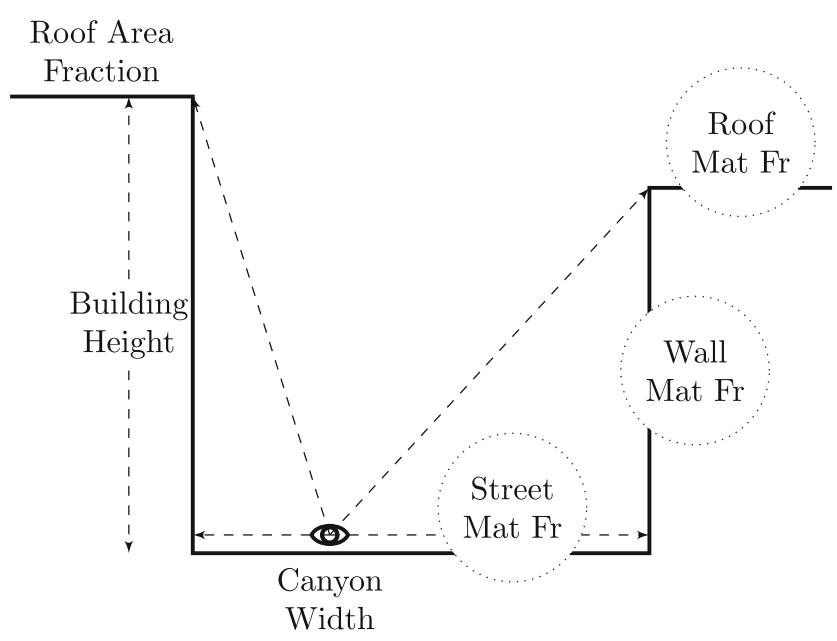

Fig. 3 Overview of the measurements taken during each stop. Material fractions (abbreviated as Mat Fr, consisting of metal, asphalt or earthenware) for roof, wall and street are estimated separately by two independent observers. A laser distance meter is used to measure building height and canyon width. Note that roof area fraction information is added afterwards from Open Street Map and Google Earth calculations

supplementing fieldwork data into the default WUDAPT LCZ mapping procedure. Second, site-specific UCP values are derived from the data for each LCZ separately.

\subsubsection{Fieldwork-derived local climate zone map}

The detailed information gathered during the fieldwork are used as training data for the built LCZ, supplemented with the natural LCZ training areas from Brousse et al. (2019). Hence, a built LCZ label is assigned to each fieldwork point, based on (i) measurements of the building height, (ii) the roof fraction derived from both Open Street Map and Google Earth and (iii) ground knowledge about easily recognizable large low-rise environments. In particular, low-rise and mid-rise classes are separated at $10 \mathrm{~m}$ building height, while open and compact classes are differentiated by $40 \%$ roof fraction. Very small (building height $<4 \mathrm{~m}$ ) and very compact (roof fraction $>60 \%$ ) environments are classified as LCZ 7. Large low-rise (LCZ 8) environments have building heights below $10 \mathrm{~m}$ and typical roof fractions within $30-50 \%$. The parameter values that are used to assign the LCZ classes are based on the definitions of Stewart and Oke (2012) and provided in Table 1. Because the characteristics for LCZ 8 partly overlap with the compact and open low-rise classes, an objective differentiation based on raw measurements is impossible. However, the large low-rise (LCZ 8) class is easily recognizable in the field as it consists of light industrial as well as commercial buildings, mainly used as storage facilities. All buildings of this LCZ 8 class take up a large area and are well separated by big roads. This allows us to easily classify them
Table 1 Morphological requirements for building height $H$ and roof fraction $R$ that define the built LCZ of each measurement. The values in the third and fifth column follow (Stewart and Oke 2012) (abbreviated as SO12), while our definitions (columns four and six) only consider an upper or lower boundary, sufficient to distinguish the different classes from each other. Large low-rise (LCZ 8) are easily recognizable, and therefore distinguished from the other classes subjectively in the field

\begin{tabular}{llllll}
\hline LCZ & LCZ name & $\begin{array}{l}R(\%) \\
(\mathrm{SO} 12)\end{array}$ & $R(\%)$ & $\begin{array}{l}H(\mathrm{~m}) \\
(\mathrm{SO} 12)\end{array}$ & $H(\mathrm{~m})$ \\
\hline 2 & Compact mid-rise & $40-70$ & $>40$ & $10-25$ & $>10$ \\
3 & Compact low-rise & $40-70$ & $>40$ & $3-10$ & $<10$ \\
5 & Open mid-rise & $20-40$ & $<40$ & $10-25$ & $>10$ \\
6 & Open low-rise & $20-40$ & $<40$ & $3-10$ & $<10$ \\
7 & Informal settlement & $60-90$ & $>60$ & $2-4$ & $<4$ \\
8 & Large low-rise & $30-50$ & - & $3-10$ & - \\
\hline
\end{tabular}

in the field. Once all points are classified, a circle around each point builds the urban training polygons. A radius of $50 \mathrm{~m}$ is chosen to avoid overlap between different polygons. However, two measurements at both sides of the road result in two LCZ labels per training circle. Because training areas have to be uniquely labelled, conflicting labels are manually removed from the training set. It is important to note, however, that this removal does not suggest unreliable measurements, as some streets indeed form the boundary between different $\mathrm{LCZ}$ neighbourhoods.

This new LCZ training data set then feeds into the random forest classifier implemented in Google's Earth Engine as prescribed by the adaptive WUDAPT protocol Demuzere et al. (2019a, b). By using the same earth observation input features used in Brousse et al. (2019) for the random forest classifier (composites of Landsat 8 bands, Sentinel 1 backscatter, minimum and maximum Normalized Difference Vegetation Index from Landsat 8, and the Normalized Difference Urban Index as given by Zhang et al. (2015)) the simulation domain is mapped into LCZ at $100 \mathrm{~m}$ horizontal resolution.

\subsubsection{Site-specific urban canopy parameters}

The fieldwork data set includes building height, road width and building-to-road measurements per point; thus, UCP values for $H$ and $\frac{h}{w_{c}}$ can be derived. Moreover, roof fraction $R$ per measurement location is calculated from Open Street Map and Google Earth. Additionally, radiative and thermal UCP are derived from the estimates of average material fractions $(\chi)$ per building combined with a lookup table of the material properties from Jackson et al. (2010) (Table 2). This is done separately for streets, walls and roofs:

$\phi_{\text {street } / \text { wall } / \text { roof }}=\sum_{i} \chi_{i} \phi_{i}$, 
with $\phi$ representing the four radiative and thermal UCPs $\left(\alpha, \epsilon, C_{v}\right.$ and $\lambda$ ), while $i$ loops over the different material categories: metal, asphalt and earthenware. The resulting road, wall and roof information are then combined to form bulk UCPs, following (Wouters et al. 2016):

$$
\begin{aligned}
\phi_{\text {rad, bulk }}= & (1-R) \frac{\phi_{\text {street }}+2 \frac{h}{w_{c}} \phi_{\text {wall }}}{1+2 \frac{h}{w_{c}}} \exp \left(-0.6 \frac{h}{w_{c}}\right) \\
& +R \phi_{\text {roof }} \\
\phi_{\text {th, bulk }}= & (1-R)\left(\phi_{\text {street }}+2 \frac{h}{w_{c}} \phi_{\text {wall }}\right)+R \phi_{\text {roof }},
\end{aligned}
$$

with Eq. 2 being valid for both $\alpha$ and $\alpha_{t h}=1-\epsilon$, and Eq. 3 being valid for both $C_{v}$ and $\lambda$. The ISA estimates from the fieldwork were unusable, since large inconsistencies were detected between estimates from different independent observers. Also remote sensing products are too uncertain over the region at such high resolution (Kaspersen et al. 2015; De Colstoun et al. 2017). Therefore this UCP is derived following the standard WUDAPT protocol, and are taken as the median value per LCZ class suggested by Stewart and Oke (2012).

\subsubsection{High-resolution local climate zone and urban canopy parameter maps}

Estimates for each climate-relevant bulk UCP are available per measurement location, to which also an LCZ class has been assigned. Combining this information produces UCP distributions per LCZ, from which the mean is taken as representative value. Each UCP is then extrapolated to the model domain of interest by applying the mean values to the corresponding classes of the fieldwork-derived LCZ map, resulting in UCP maps at $100 \mathrm{~m}$ resolution. These sitespecific high-resolution UCP maps can be considered as a basis input for many urban climate studies. As an example, we show the application to the COSMO-CLM regional climate model including the TERRA_URB scheme.

\subsection{Urban climate modelling}

\subsubsection{Regional climate model}

To demonstrate the effects of site-specific urban surface information on the local climate, the regional climate model COSMO-CLM 5.0 (Rockel et al. 2008) is used. In the dynamical core of the model, prognostic variables are calculated on an Arakawa C-grid by numerically solving the set of primitive equations (Doms et al. 2011). Furthermore, the dynamical core of the model is fed with source and sink terms from physical parametrization schemes accounting for subgridscale processes that describe radiative transfer (Ritter and
Table 2 Radiative and thermal material properties: albedo $(\alpha)$, emissivity $(\epsilon)$, volumetric heat capacity $\left(C_{v}\right)$ and heat conductivity $(\lambda)$ for three material categories. From: Jackson et al. (2010)

\begin{tabular}{lllll}
\hline Material & $\alpha(-)$ & $\epsilon(-)$ & $C_{v}\left(10^{6} \mathrm{JK}^{-1} \mathrm{~m}^{-3}\right)$ & $\lambda\left(\mathrm{W} \mathrm{K}^{-1} \mathrm{~m}^{-1}\right)$ \\
\hline Corrugated metal & 0.17 & 0.13 & 2.97 & 68.5 \\
Asphalt & 0.13 & 0.91 & 1.93 & 1.2 \\
Earthenware & 0.23 & 0.90 & 1.70 & 1.2 \\
\hline
\end{tabular}

Geleyn 1992), turbulence (Mironov and Raschendorfer 2001), microphysical cloud processes as well as shallow convection (Tiedtke 1989). All surface-atmosphere interactions are parametrized by one-dimensional parametrization schemes: lake processes by FLake (Mironov et al. 2010), land processes by TERRA-ML (Schulz et al. 2015), and urbanatmosphere interactions by TERRA_URB (Wouters et al. (2016), see Section 2.4.2).

The COSMO-CLM model with FLake coupled has been extensively used in the Lake Victoria region, first by Thiery et al. (2015) at $7 \mathrm{~km}$ resolution, after extensive offline testing of FLake Thiery et al. (2014b, 2014a). Recently, a multi-year convection-permitting $(\sim 2.8 \mathrm{~km})$ simulation was performed, focusing on the complex effects of the lake, synoptic wind and mountains on the regional climate (Van de Walle et al. 2020b). The first performance tests of COSMO-CLM including TERRA_URB in this region was accomplished by Brousse et al. (2020), simulating at $1 \mathrm{~km}$ grid spacing over the city of Kampala.

Here, the model is used with an identical configuration as described in Brousse et al. (2020), based on its tropical setup (Panitz et al. 2014) with an extension of the soil-moisture heat conductivity formulation (Schulz and Vogel 2020). The latter represents vegetation in the surface energy balance, thereby introducing a temperature for the vegetation layer and accounting for insulating effects by the vegetation in the default surface land parametrization scheme TERRAML (Schulz et al. 2015). A three-step downscaling strategy is applied from ERA-Interim (Dee et al. 2011) over coarseresolution $(12 \mathrm{~km})$ nesting step to a high-resolution $(1 \mathrm{~km})$ domain centred on the city of Kampala. The coarseresolution multi-year simulation is available from January 2005 to February 2018, but only a short period has been further downscaled to $1 \mathrm{~km}$, in particular the three dry season months from December 2017 to February 2018 (Brousse et al. 2020).

\subsubsection{Urban parametrization scheme}

The urban parametrization scheme TERRA_URB (Wouters et al. 2016) supplements the default TERRA-ML surface scheme (Schulz et al. 2015). It improves the city representation by indirectly accounting for shadowing and multiple 
scattering of radiation, heterogeneous surface-atmospheric interaction in terms of turbulent momentum, heat and moisture transport and the inner-building energy budget. Instead of explicitly calculating these processes, a Semi-empirical URban canopy dependencY algorithm (SURY; Wouters et al. (2016)) condenses three-dimensional canopy information to a limited number of bulk properties, thereby strongly reducing the computational cost without loss of performance Wouters et al. (2016, 2017), Demuzere et al.
(2017). The TERRA_URB urban parametrization scheme is fed with the following morphological, thermal and radiative UCPs in the form of surface bulk input fields at the climate model's resolution: impervious surface area fraction (ISA), building height $(H)$, roof area fraction $(R)$, height-to-width ratio $\left(\frac{h}{w_{c}}\right)$, volumetric heat capacity $\left(C_{v}\right)$, heat conductivity $(\lambda)$, shortwave albedo $(\alpha)$ and thermal albedo $\left(\alpha_{t h}\right)$. The latter is defined as one minus thermal emissivity $\left(\alpha_{t h}=1-\epsilon\right)$.
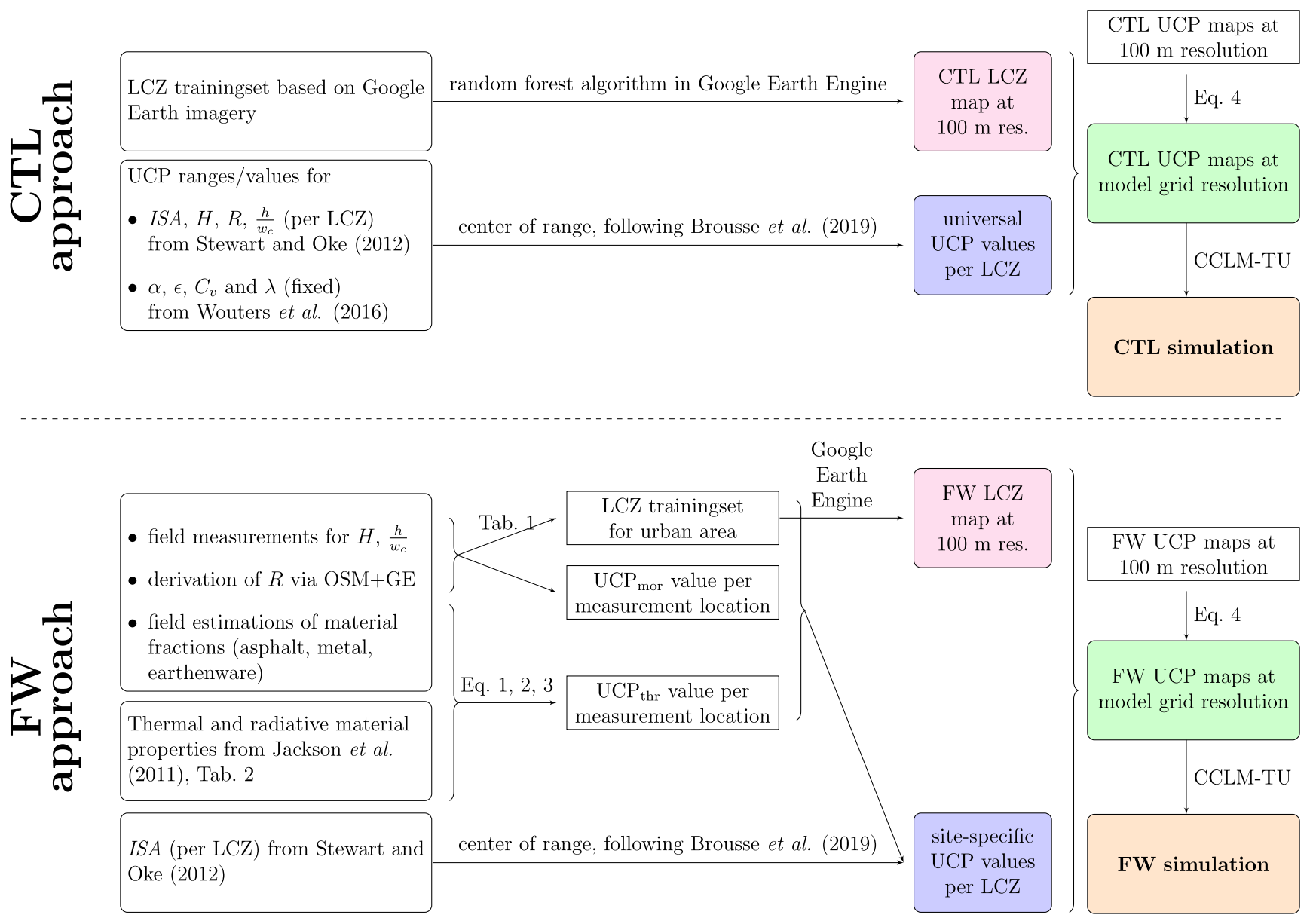

Fig. 4 Data flow chart for both control (CTL) and fieldwork (FW) simulations. The CTL procedure follows the standard WUDAPT protocol: the user starts creating an LCZ training set that exemplifies LCZ areas based on Google Earth (GE) imagery. The training set serves the random forest algorithm (implemented as a Google Earth Engine script) that extrapolates the training set to the model study domain. The resulting LCZ map has a resolution of $100 \mathrm{~m}$. Next, the user derives urban canopy parameter (UCP) values, for instance from UCP ranges per LCZ proposed by Stewart and Oke (2012), or from city-invariant, fixed values proposed by Wouters et al. (2016). Combining the LCZ map and UCP values per LCZ results in UCP maps at $100 \mathrm{~m}$ resolution, which are then remapped to a coarser resolution to match the climate model grid, here at $1 \mathrm{~km}$ resolution. These UCP maps contain all surface information necessary for the urban parametrization scheme of the climate model (TERRA_URB embedded in COSMO-CLM, abbreviated as CCLM-TU). The input, and therefore also the FW procedure, differs in many aspects. Building height $H$ and height-to-width ratio $\frac{h}{w_{c}}$ are gathered during sitespecific fieldwork measurements, as well as estimates of material fractions. Roof fraction $R$ is derived from Open Street Map (OSM) and $\mathrm{GE}$, and the value for $I S A$ is derived following the standard procedure. Derivations for morphological $\left(\mathrm{UCP}_{\mathrm{mor}}\right)$ and radiative and thermal urban canopy parameters $\left(\mathrm{UCP}_{\mathrm{thr}}\right)$ are different. The text box colours refer to figures discussed later. Red: both LCZ maps are compared in Fig. 5. Blue: UCP values per LCZ are shown in Fig. 6. Green: the UCP maps serving as input to the climate model are summarized in Fig. 7, while Fig. S3 shows the UCP distributions. They are discussed in Section 3.1, Sections 3.2 and 3.3. Orange: climate comparisons are provided in Figs. 8 and 9. These results build Section 3.4 


\subsubsection{Implementation of site-specific fieldwork-derived urban canopy parameters}

All these UCPs are available from the fieldwork data. However, to deliver the fieldwork data in the form of surface bulk input fields to the urban parameterization scheme TERRA_URB, an additional step is required: the remapping of the high-resolution UCP maps to the coarser grid of the climate model $(1 \mathrm{~km})$. For $I S A$, the highresolution pixels $(100 \mathrm{~m})$ are averaged over an area of $1 \mathrm{~km}$ while being remapped to the coarser grid. This is called an Area-weighting. For other UCPs however, an ISAweighted mean is applied, ensuring the conservation of the city characteristics after remapping to coarser resolution:

$U C P_{1 \mathrm{~km}}=\frac{\sum_{\mathrm{j} \in 1 \mathrm{~km}} U C P_{100 \mathrm{~m}, \mathrm{j}} I S A_{100 \mathrm{~m}, \mathrm{j}}}{\sum_{\mathrm{j} \in 1 \mathrm{~km}} I S A_{100 \mathrm{~m}, \mathrm{j}}}$,

where $j$ selects each $100 \mathrm{~m}$ resolution cell within the coarse $1 \mathrm{~km}$ pixel. This aggregation methodology has been applied by Varentsov et al. (2020), and is formalized in a freely available online tool (https://github.com/matthiasdemuzere/ WUDAPT-to-COSMO).

\subsubsection{Model experiments and evaluation}

To assess the impacts of the site-specific data on the modelled surface temperature $\left(T_{S}\right)$ and near-surface air temperature $\left(T_{2 m}\right)$, two regional climate simulations are performed. The input fields for the first control simulation (CTL) are derived following the standard WUDAPT protocol. Except for the Area-weighted and the ISA-weighted remapping, the approach is identical to the one described by Brousse et al. (2020), that used a conservative remapping of second-order
(Jones 1999) to upscale UCPs. A summary of the data flow is given in the upper part of Fig. 4. The data flow resulting in the input fields for the second, site-specific simulation (FW) was described in Section 2.3 and is schematically summarized in the lower half of Fig. 4.

Simulation results for surface temperature are evaluated against the Moderate Resolution Imaging Spectroradiometer (MODIS) data from the polar-orbiting TERRA and AQUA satellites (Wan et al. 2004; Wan 2007). Each satellite overpasses twice a day over Kampala around 10:30 local time (TERRA) and 13:30 (AQUA) during daytime, and around 22:30 (TERRA) and 01:30 (AQUA) during nighttime. The high horizontal resolution $(\sim 1 \mathrm{~km})$ is in good agreement with the simulation resolution. Differences between the CTL and FW simulation are assessed over the CTL urban extent (ISA>0.1). Furthermore, nearsurface temperatures are evaluated against nine TransAfrican Hydro-Meteorological Observatory (TAHMO, van de Giesen et al. (2014)) automatic weather stations located within a radius of $100 \mathrm{~km}$ around the centre of Kampala. We note that all stations except Entebbe and Makerere are located outside the CTL urban extent. Due to this sparse network, the evaluation only applies to the overall model performance, not to intra-urban variations.

\section{Results}

\subsection{Spatial distribution of local climate zones}

The LCZ map derived following the generic WUDAPT protocol (named CTL) and the map derived directly from our fieldwork (named FW) are compared. Visual inspection
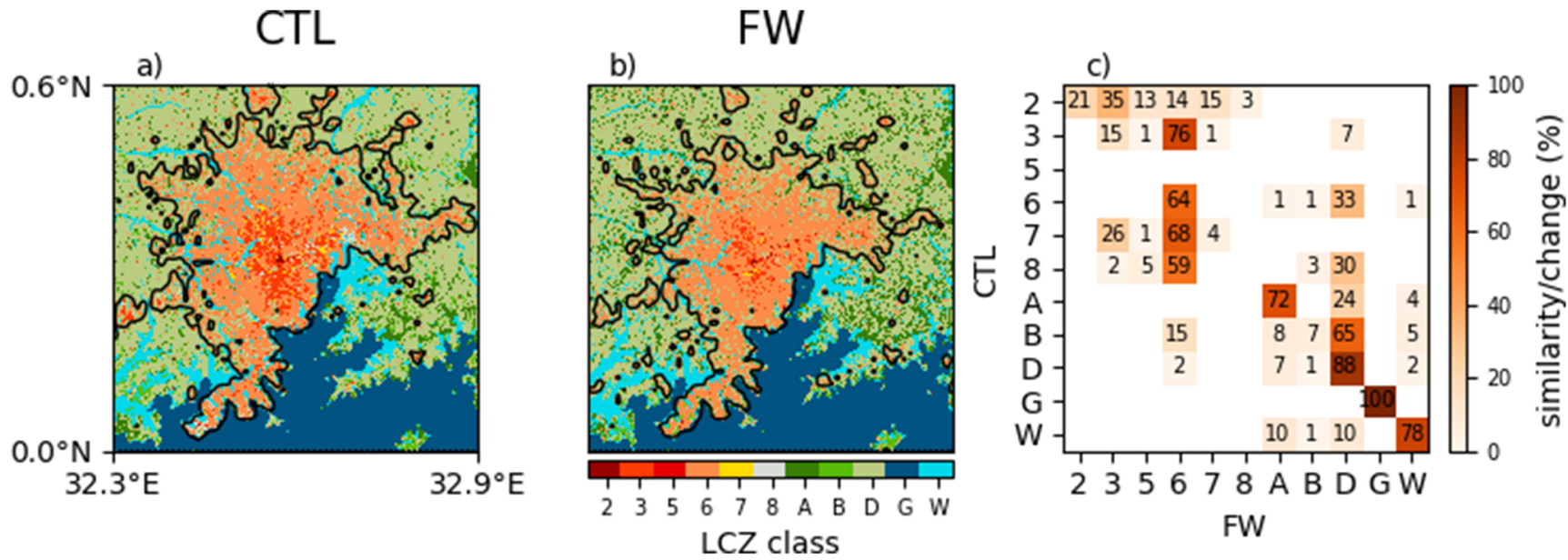

Fig. 5 Comparison of the LCZ maps from (a) CTL and (b) FW over the evaluation domain. The black contour lines show the urban extension for both maps, defined as $I S A>0.1$. (c) Percentage similarity/change for each LCZ class, to be read from CTL (ordinate) to FW (abscissa). Each row in this comparison matrix adds up to (rounded) $100 \%$, except the open mid-rise class (LCZ 5) which was not considered in CTL. The overall accuracies of the map, as well as the accuracies of each class separately are shown in Fig. S1 
of both maps reveals clear differences (Fig. 5a and b). First, the overall urban extent, defined as $I S A>0.1$ and shown by the black contour line, is lower in FW. Second, the fraction of compact built LCZ classes types is reduced and replaced by open low-rise (LCZ 6). All similarities and changes are quantified in the comparison matrix (Fig. 5c). As an example on the interpretation of this matrix, we consider the upper left cells. Only $21 \%$ of compact mid-rise
(LCZ 2) pixels in CTL close to the city centre are similarly classified in FW, while 35\% has changed to compact lowrise (LCZ 3). Over three quarter of the compact low-rise areas (LCZ 3) is reclassified as open low-rise (LCZ 6). Besides this reclassification of compact low-rise (LCZ 3), $14 \%$ of LCZ 2 in the central business district, $68 \%$ of the informal settlements (LCZ 7) and 59\% of the large low-rise (LCZ 8) are changed to LCZ 6 in the FW map. The overall
Fig. 6 (a-d) Comparison of site-specific fieldwork (FW) observed urban canyon parameter distributions (UCP, shown as boxplots) with (i) values used in the control (CTL) approach, copied from Brousse et al. (2020, orange filled dots), and (ii) universal ranges from Stewart and Oke (2012, SO12, blue bars). (e-h) Distributions for radiative and thermal UCP are derived from material fraction estimates (Fig. S2) and material properties (Table 2), following Eqs. 1, 2 and 3. FW UCP distributions are compared against the CTL values proposed by Wouters et al. (2016, W16, orange open dots) and applied by (Brousse et al. 2020). The UCP include impervious surface fraction (ISA), building height $(H)$, roof fraction $(R)$, heightto-width ratio $\left(h / w_{c}\right)$, albedo $(\alpha)$, emissivity $(\epsilon)$, heat capacity $\left(C_{v}\right)$ and conductivity $(\lambda)$ for the six built LCZ clases compact mid-rise (LCZ 2), compact low-rise (LCZ 3), open mid-rise (LCZ 5), open low-rise (LCZ 6), informal settlements (LCZ 7) and large low-rise (LCZ 8)
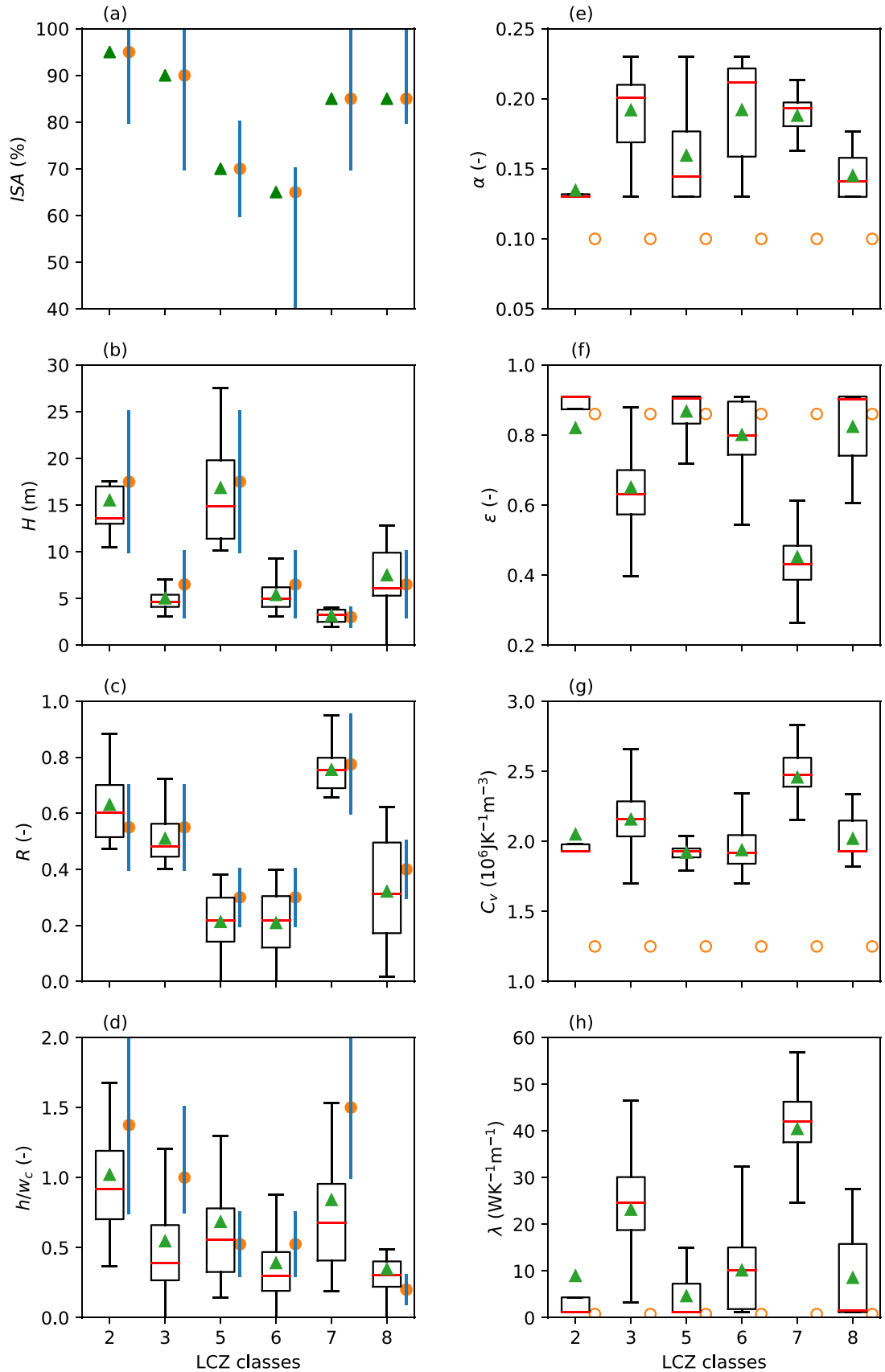

- SO12 range
CTL mean $\quad \begin{aligned} & \text { W16 values } \\ & \text { FW median }\end{aligned}$


reduction of urban extent as seen in the maps, also appears in this comparison matrix, as one-third of the open low-rise areas (LCZ 6) changes to vegetated areas with low plants (LCZ D). The informal settlements of CTL have almost completely been reclassified, as only $4 \%$ of the LCZ 7 pixels are identical in both maps.

The substantial changes in both LCZ maps are also depicted in the accuracy measures (Fig. S1). For the central business district, the informal settlements and large lowrise (LCZ 2, LCZ 7 and LCZ 8, respectively), accuracies increase by $10-20 \%$. The open low-rise class (LCZ 6) continues to have the highest accuracy $(\sim 0.8)$. From all built classes, only the accuracy of compact low-rise (LCZ 3) decreases with almost 20\%. Training areas for open mid-rise (LCZ 5) were not identified, excluding this class in the CTL map. However, some fieldwork measurement locations were classified as LCZ 5, adding this class to the FW LCZ map. The mean accuracy of approximately 0.1 suggests that the $\mathrm{LCZ}$ mapping experiences difficulties in recognizing and distinguishing this class, probably caused by the lack of proper building height data in the classification process (Vandamme et al. 2019). Despite these clear accuracy changes per LCZ, the overall accuracy $(\mathrm{OA})$ is very similar between CTL and FW LCZ maps.

\subsection{Urban canopy parameters per local climate zone}

The differences between the CTL and FW LCZ maps also alter the UCP values per LCZ class (Fig. 6, for which the means are summarized in Table S1). Except for ISA, distributions of fieldwork measurements are summarized as boxplots per LCZ class. For the morphological UCPs (building height, roof fraction and height-to-width ratio), the first and third quartiles of the distributions are compared against the universal UCP ranges of Stewart and Oke (2012), while the mean is compared against the values derived following the CTL procedure, also applied in Brousse et al. (2020). Even though the morphological
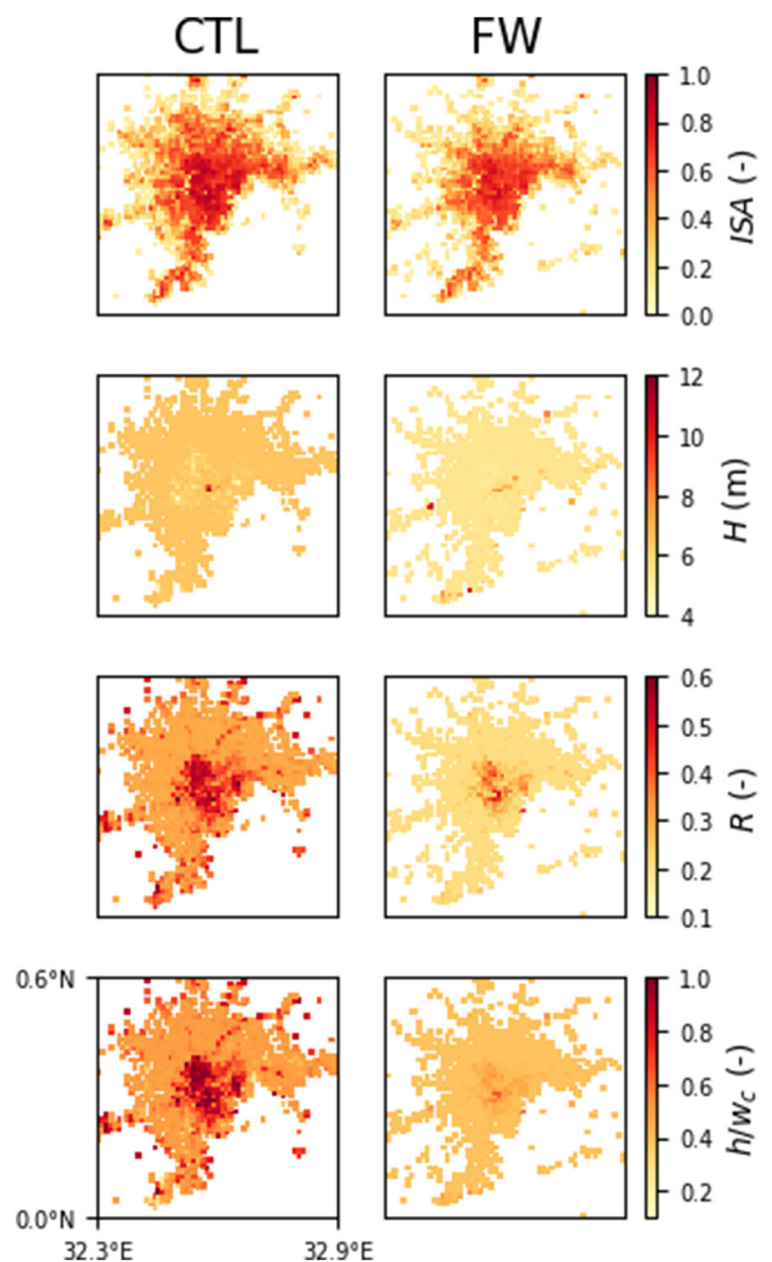

Fig. 7 Urban canopy parameter (UCP) fields at the remapped $1 \mathrm{~km}$ resolution grid for both the control (CTL) and fieldwork (FW) approaches. The UCP include impervious surface fraction (ISA), building height
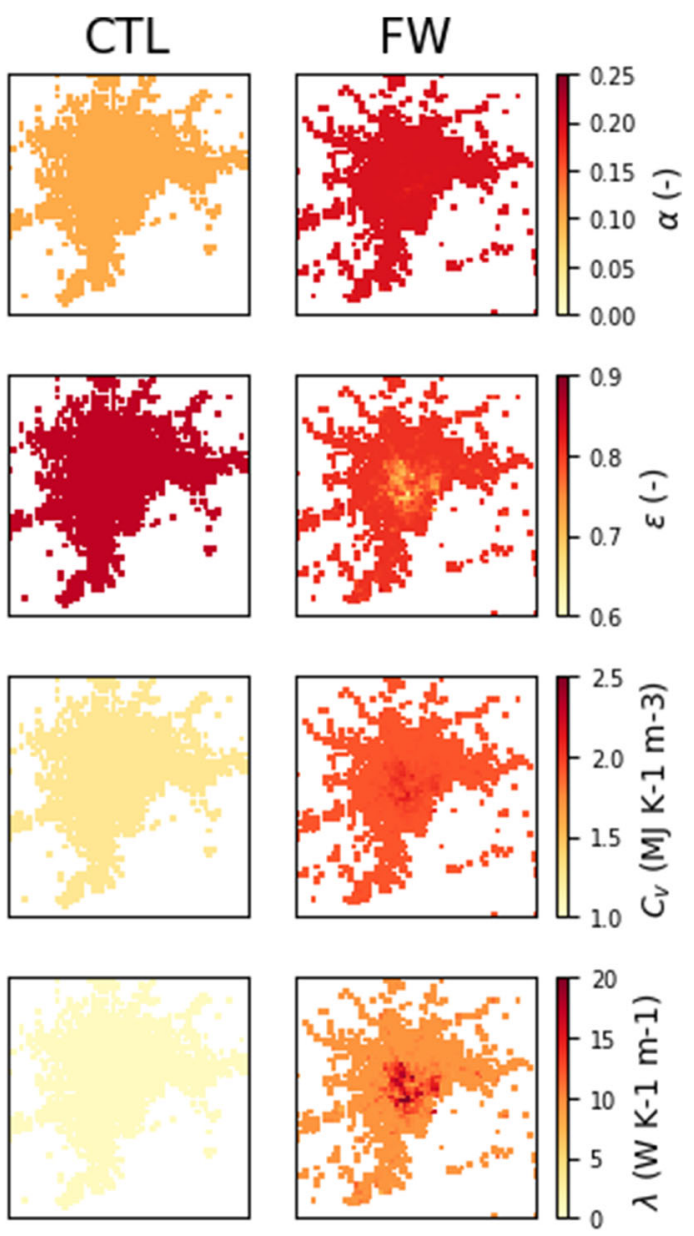

$(H)$, roof fraction $(R)$, height-to-width ratio $\left(h / w_{c}\right)$, albedo $(\alpha)$, emissivity $(\epsilon)$, heat capacity $\left(C_{v}\right)$ and conductivity $(\lambda)$ 
UCP values for CTL and FW generally agree very well, mean values for height-to-width ratio substantially differ, especially for the densely built environments (LCZ 2, 3 and 7 ). These differences can probably be explained by wider site-specific street canyons measured in Kampala compared to the universal values. This result suggests that the LCZ classification in Kampala could potentially benefit from the use of subclasses as introduced by Stewart and Oke (2012).

For radiative and thermal UCPs, larger differences between CTL and FW are observed, which are analysed considering both material properties (Table 2) and sitespecific material fraction estimates (Fig. S2). These material fraction estimates suggest that street canyons in the city centre (LCZ 2) are constructed almost completely out of concrete/asphalt. Asphalted roads are also observed in LCZ 5 and LCZ 8, the open mid-rise and large lowrise areas. Especially in LCZ 3 and LCZ 7, corrugated metal is an abundant material, mainly used for roofs. While earthenware in these classes mainly appears from compressed earth (murrum) roads, the earthenware fraction in LCZ 5 and LCZ 6 is attributed to brick walls and red tile roofing. These fraction estimates are combined following Eqs. 1, 2 and 3, resulting in the radiative and thermal FW distributions (Fig. 6), which are compared against the cityinvariant values proposed by Wouters et al. (2016) and applied in Brousse et al. (2020). While albedo and heat capacity are substantially higher in each class, changes in emissivity and thermal conductivity are most pronounced in compact low-rise and informal settlements (LCZ 3 and LCZ 7). In these classes, corrugated metal was shown to be an abundant material in the street canyon and is characterized by a very low emissivity and a very high conductivity (Table 2).

\subsection{Spatial distribution of urban canopy parameters}

Following Eq. 4, UCP fields are remapped to a coarser resolution grid (Figs. 7 and S3). For the FW-derived results, ISA is lower throughout the city, mainly caused by the changes in LCZ classes: the open low-rise class (LCZ 6) to vegetation types in the suburbs and compact low-rise (LCZ 3) to the more open LCZ 6 neighbourhood in the city (Fig. 5). Decreases in building height, roof fraction and height-towidth ratio are the combined results of changes in LCZ classes and changes of UCP values per LCZ. Systematic changes in the radiative and thermal UCP maps are large. For albedo and heat capacity they even exceed intra-urban variations. Overall, we conclude that the derivation of urban parameters via the LCZ universal parameters (CTL) or via site-specific measurements (FW) results in substantially different UCP input fields.

\section{4 (Near-)surface temperature modelling}

Given the differences in LCZ and UCP maps between the CTL and FW approaches (Figs. 5 and 7), changes in
Fig. 8 Hourly averaged modelled surface temperatures $\left(T_{s}\right)$ and near-surface temperatures at $2 \mathrm{~m}\left(T_{2 m}\right)$ of the control simulation (CTL) in the left panels and their respective mean differences between the fieldwork (FW) and the control simulation in the right panels. Both simulations were run for the short dry season from December 2017 to Februari 2018. Significant differences in temperatures at the $5 \%$ confidence level are hatched in green
CTL
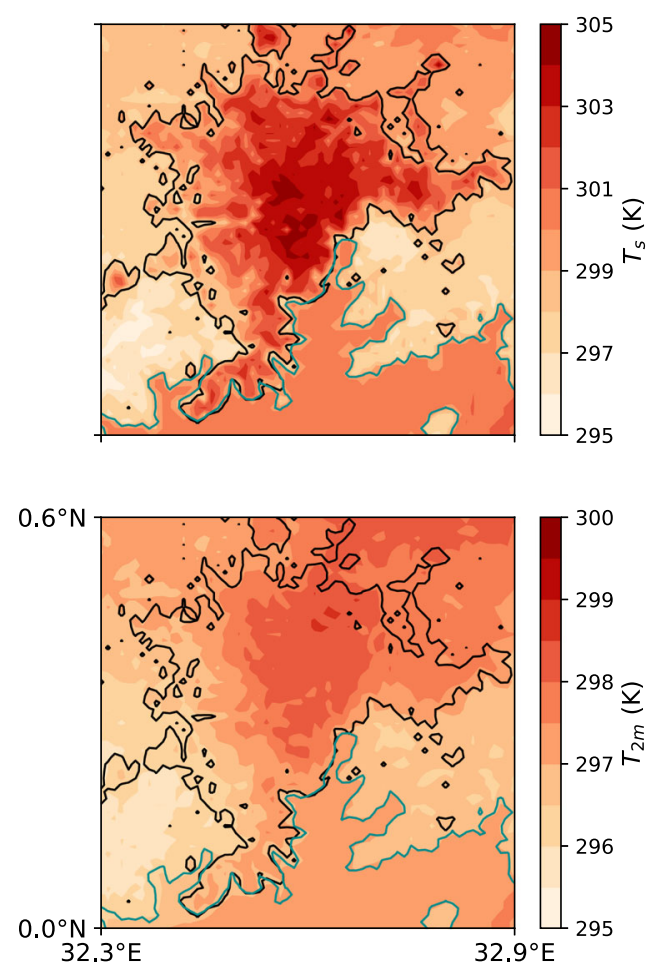
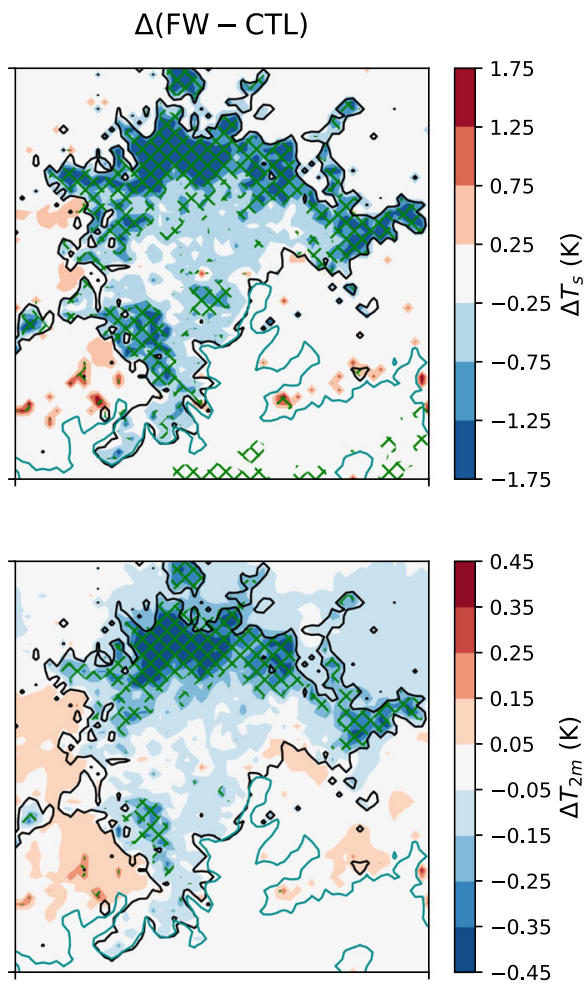
Table 3 Mean bias, root mean squared error (RMSE), and Perkins Skill Score (PSS) for simulated surface temperature $\left(T_{S}\right)$ against MODIS observations from both TERRA and AQUA satellites, each overpassing the domain twice a day. Differences between the biases from the two model runs are all significant at the $5 \%$ confidence level. Note that this evaluation is performed over the same evaluation domain as Brousse et al. (2020; Fig. 2 herein), with latitude $\left[0.0^{\circ}, 0.6^{\circ} \mathrm{N}\right]$ and longitude $\left[32.3^{\circ}\right.$ E, $32.9^{\circ}$ E]. Hours are in local time

\begin{tabular}{llll} 
TERRA & AQUA & TERRA & AQUA \\
$(10: 30 \mathrm{AM})$ & $(1: 30 \mathrm{PM})$ & $(10: 30 \mathrm{PM})$ & $(1: 30 \mathrm{AM})$ \\
\hline
\end{tabular}

\begin{tabular}{lllll}
\hline Mean bias (K) & & & & \\
CTL & 5.93 & 7.06 & 4.57 & 3.80 \\
FW & 3.69 & 4.46 & 4.24 & 3.31 \\
RMSE (K) & & & & \\
CTL & 6.94 & 8.03 & 4.71 & 3.94 \\
FW & 4.78 & 5.85 & 4.42 & 3.50 \\
PSS (-) & & & & \\
CTL & 0.45 & 0.38 & 0.20 & 0.24 \\
FW & 0.60 & 0.56 & 0.26 & 0.33 \\
\hline
\end{tabular}

modelled (near-)surface temperatures are expected. Overall, the implementation of site-specific UCPs leads to an overall cooler modelled urban environment (Fig. 8). While $T_{s}$ is reduced by approximately $1 \mathrm{~K}$ on average and down to $2 \mathrm{~K}$ in the outskirt of the urban area, urban near-surface air temperatures are reduced by approximately $0.2 \mathrm{~K}$ to $0.6 \mathrm{~K}$. Differences are most significant over the outskirts, where open low-rise (LCZ 6) urban pixels in CTL are replaced
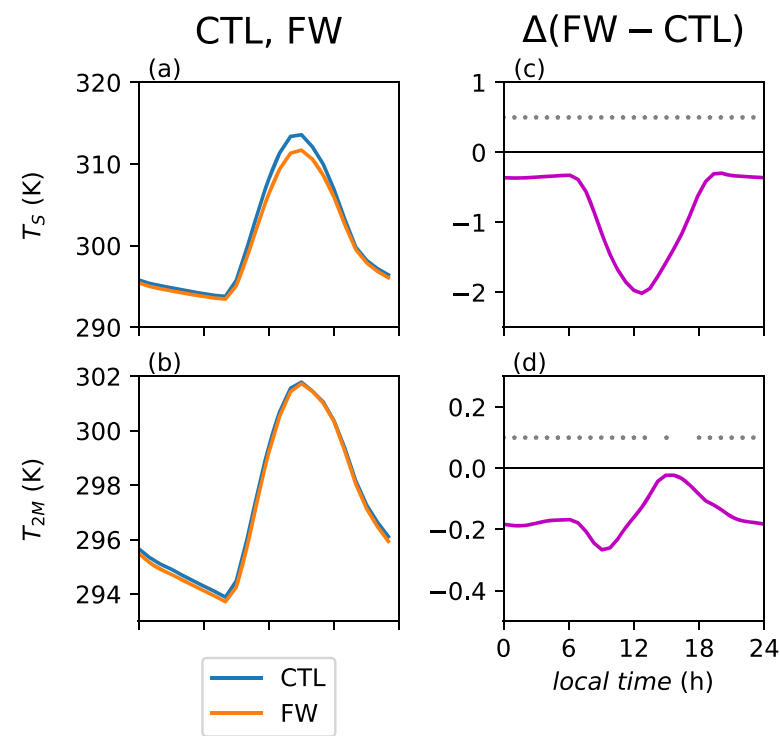

Fig. 9 (a,b) Diurnal cycle of surface and near-surface temperature for both CTL and FW runs. (c,d) Difference of FW against the CTL simulation, averaged over the CTL urban extent $(I S A>0.1)$. This difference is the combined effect of (i) an updated LCZ map, (ii) the site-specific morphological and (iii) site-specific spatially variable thermal and radiative UCP per LCZ. Statistically significant (5\% confidence level) by vegetation class LCZ D (Fig. 5), reducing the ISA fraction (Fig. 7). On the contrary, temperature differences over the central parts of the city are minor and mostly insignificant.

The overall cooler urban surface leads to an improved performance for $T_{S}$ of the FW simulation against CTL. In fact, when evaluating the modelled urban surface temperatures against MODIS, both the mean bias and the root mean squared error are significantly reduced, especially during daytime (Table 3). Air temperature at $2 \mathrm{~m}$ in the broader Kampala region is evaluated against observations from nine TAHMO weather stations (van de Giesen et al. 2014), resulting in very similar scores between CTL and FW (Table S2). This result is not surprising, as all stations except Entebbe and Makerere are located outside the CTL urban extent, and those two fall outside the region characterized by statistically significant differences between CTL and FW near-surface temperatures (Fig. 8). This evaluation therefore only applies to the overall model performance, not to intraurban near-surface temperature variability.

Averaged over the CTL urban extent $(I S A>0.1)$, surface temperature differences between CTL and FW are statistically significant throughout the day, with largest differences during daytime when FW is up to $2 \mathrm{~K}$ cooler (Fig. 9 a,c). Mean near-surface temperature differences are smaller, with FW being $\sim 0.2 \mathrm{~K}$ cooler than CTL during nighttime and morning, but nearly identical in the afternoon (Fig. 9 b, d).

Intra-urban temperature differences between CTL and FW are investigated by selecting pixels that share a

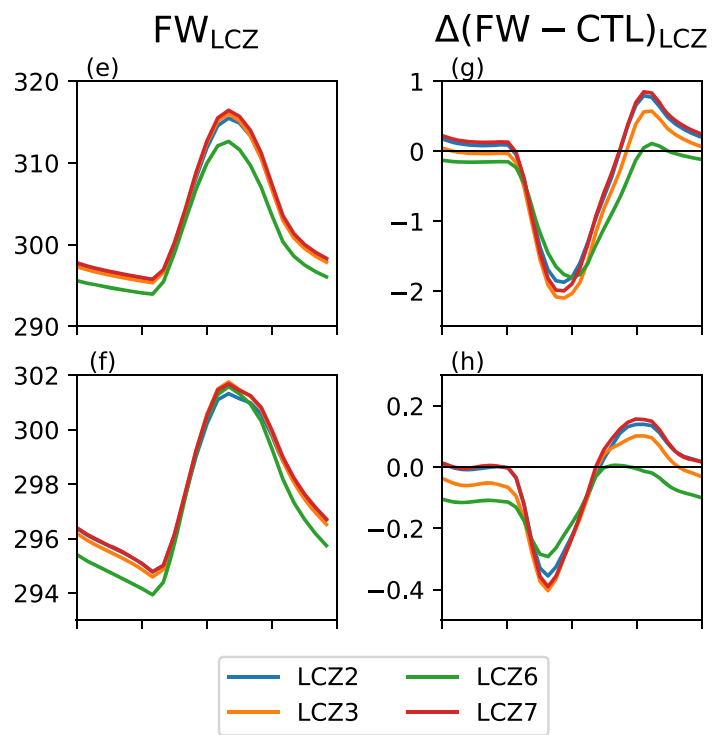

differences between the simulation are indicated per hour by grey stars. $(\mathrm{e}, \mathrm{f})$ Diurnal cycles of the FW simulation distinguishing different LCZ. The open mid-rise (LCZ 5) and large low-rise (LCZ 8) had no or too few common pixels between CTL and FW, thus excluded from the figure. $(\mathrm{g}, \mathrm{h})$ Differences between FW and CTL per LCZ. Note that only pixels are selected with identical LCZ classes between CTL and FW 
common LCZ class in both approaches. Shared open lowrise (LCZ 6) locations are clearly cooler than others, during daytime and nighttime for surface temperature, and especially during nighttime for near-surface temperature (Fig. 9 e, f). While not present in the open low-rise (LCZ 6) signal, (near-)surface afternoon temperatures are higher in FW compared to CTL in compact mid-rise (LCZ 2), compact low-rise (LCZ 3) and informal settlements (LCZ 7) (Fig. 9 g, h). In the latter classes, the FW introduces higher values for the thermal properties $C_{v}$ and $\lambda$ (Fig. 6), possibly forming a larger and easier accessible heat reservoir. As this reservoir might store more heat before noon and release more heat in the late afternoon, it can explain this particular $T_{s}$ and $T_{2 m}$ signal.

\section{Discussion and conclusions}

In this study we demonstrated that site-specific field-derived observations of the urban forms and building materials provide a different physical description of the city in comparison to a universal approach. To properly interpret this result, we discuss the advantages and limitations of the data gathering and processing procedures as well as the universal approach, keeping in mind its potential usage in urban climate studies.

First, the measurements taken at fixed stops along transects unavoidably include nonrepresentative locations within one LCZ environment. As an example, the walks also pass big streets through compact LCZ classes. These big streets might thus be included in the site-specific UCP distribution of that class. However, such open areas are not included in the universal UCP ranges (Stewart and Oke 2012), since they do not exemplify the compact zone. This mismatch might partly explain the lower measured heightto-width ratio in densely built environments compared to the universal UCP ranges.

Second, applying a different methodology to obtain a training set can lead to a different resulting LCZ map. Two factors play a role in explaining those differences. On the one hand, the site-specific LCZ training set probably has the highest quality, thanks to the objective and threedimensional information about the street canyon. This is advantageous over the standard WUDAPT classification procedure that is prone to subjective biases and that uses training polygons based on two-dimensional Google Earth images (Bechtel et al. 2017; Verdonck et al. 2019). On the other hand, the standard WUDAPT procedure is userfriendly and allows the user to quickly produce a large training set, while the site-specific LCZ training set is limited to small areas enclosing the measuring points. Possibly, the optimal LCZ map has to benefit from the advantages of both approaches.
Third, this different LCZ classification has a direct impact on the spatial distribution of the ISA fraction, a very important parameter for urban studies (Weng 2012). Impervious surface has emerged as indicator of the degree of urbanization, but also as indicator of environmental quality (Arnold and Gibbons 1996). Therefore, the uncertainty about the spatial distribution of the ISA fraction has to be reduced. Yet, deriving ISA from fieldwork campaigns faces an important challenge which we experienced during our fieldwork exercise. Two observers independently estimated ISA at each measuring location, but often resulted in very inconsistent values due to the interpretation of the perviousness of unpaved but tamped earth. Therefore, impervious surface fractions could alternatively be retrieved from remote sensing techniques (Weng 2012; Kaspersen et al. 2015; Kamusoko 2017), providing products up to $\sim 30 \mathrm{~m}$ resolution such as the Global Man-made Impervious Surface (GMIS, De Colstoun et al. 2017). Though the latter is also available for the city of Kampala, they acknowledge the challenge of proper ISA representation in cities with areas of bare soil, similar to our fieldwork experience.

Fourth, the thermal properties of materials are characterized by larger uncertainties than morphological parameters. For example, all urban canyon materials are divided into only three groups (metal, asphalt and earthenware), but more groups would naturally result in more precise thermal characteristics. In addition, some thermal properties are highly sensitive to the exact composition of that material. For painted walls for example, it is not trivial to see whether the underlying material is concrete or bricks. Moreover, material fraction estimates per selected building at each measuring location are prone to individual observer interpretations. Attempting to reduce this subjectivity, two observers estimate independently from each other. More independent estimates or better protocols could lead to more reliable results, but also access to information from building companies or dedicated fieldwork specifically on materials would be beneficial. Nevertheless, our study is the first attempt in tropical Africa to acquire such information on the building materials.

Despite these limitations, our method for deriving sitespecific morphological, thermal and radiative UCPs showed its relevance over the data-scarce city of Kampala while using our results in an urban climate modelling exercise. The fieldwork-derived LCZ map and the site-specific parameters resulted in an overall lowering of near-surface temperatures, especially during the day. This result was mainly attributed to a higher vegetation fraction in the city outskirts. The importance of vegetation fraction in determining local temperature variations in tropical African cities was already suggested by observations (Scott et al. 2017). In addition, the new representation of Kampala in the climate model resulted in higher afternoon temperatures in 
the densely built environments (LCZ 2, 3 and 7) compared to the control run not including any site-specific data. These high temperatures are hypothesized as an effect of more heat storage at noon and more efficient heat transfer from the ground in the afternoon, due to the use of metal as building material.

Three important outcomes follow from this study. First, up-to-date and detailed parameters on the neighbourhood typologies can be obtained by fieldwork measurements, accomplished with a cost-friendly, easily applicable, efficient and practically designed methodology. Second, through the use of LCZ maps, both morphological and thermal parameters can be extrapolated to the entire city, making them particularly relevant for urban climate studies. Though we recognize that the simple averaging per LCZ of the morphological and thermal characteristics that were measured in the field can lead to uncertainties, it already provides a more site-specific influence of the tropical African city of Kampala on the local climate than the universal LCZ parameters. Third, implementing detailed site-specific measurements significantly impacts the modelled urban surface temperature, and to a lesser extent the near-surface air temperature.

Supplementary information The online version contains supplementary material available at https://doi.org/10.1007/s00704-021-03733-7.

Acknowledgements We thank the reviewers for their positive feedback and efforts towards improving the manuscript.

Author contribution The fieldwork data collection was done by Jonas Van de Walle, Oscar Brousse, Lien Arnalsteen, Disan Byarugaba, Gloria Nsangi, Hakimu Sseviiri and Roxanne Vanhaeren, led by Daniel Ddumba, Shuaib Lwasa and Nicole van Lipzig. The raw data was postprocessed by Lien Arnalsteen and Jonas Van de Walle, with the help from Matthias Demuzere and Hendrik Wouters. The urban climate model simulations were performed by Oscar Brousse. The manuscript structure was prepared by Jonas Van de Walle and Oscar Brousse, with many input from Matthias Demuzere, Hendrik Wouters, Wim Thiery and Nicole van Lipzig. All the co-authors have contributed to the final version of the manuscript.

Funding This work was financially supported by the KU Leuven Internal Special Research Fund (BOF-C1 project C14/17/053) and BELSPO (Belgian Federal Science Policy Office) in the frame of the STEREO III program, as part of the REACT (SR/00/337) project (http://react.ulb.be/).

Availability of data and material The raw fieldwork data is available online via: http://doi.org/10.5281/zenodo.3930199. The urban model output is available by contacting the first author, as well as the codes used to process the fieldwork data to spatial maps of urban canopy parameters.

Open Access This article is licensed under a Creative Commons Attribution 4.0 International License, which permits use, sharing, adaptation, distribution and reproduction in any medium or format, as long as you give appropriate credit to the original author(s) and the source, provide a link to the Creative Commons licence, and indicate if changes were made. The images or other third party material in this article are included in the article's Creative Commons licence, unless indicated otherwise in a credit line to the material. If material is not included in the article's Creative Commons licence and your intended use is not permitted by statutory regulation or exceeds the permitted use, you will need to obtain permission directly from the copyright holder. To view a copy of this licence, visit http://creativecommons. org/licenses/by/4.0/.

\section{References}

Acuto M, Parnell S (2016) Leave no city behind. https://doi.org/10. 1126/science.aag 1385

Alexander PJ, Fealy R, Mills GM (2016) Simulating the impact of urban development pathways on the local climate: A scenariobased analysis in the greater Dublin region, Ireland. Landscape and Urban Planning. https://doi.org/10.1016/j.landurbplan.2016. 02.006

Arnold Jr CL, Gibbons CJ (1996) Impervious surface coverage: the emergence of a key environmental indicator. J Am Plan Assoc 62(2):243-258. https://doi.org/10.1080/01944369608975688

Barrios S, Bertinelli L, Strobl E (2006) Climatic change and ruralurban migration: The case of sub-Saharan Africa. J Urban Econ. https://doi.org/10.1016/j.jue.2006.04.005

Bechtel B, Alexander PJ, Böhner J, Ching J, Conrad O, Feddema J, Mills G, See L, Stewart I (2015) Mapping local climate zones for a worldwide database of the form and function of cities. ISPRS International Journal of Geo-Information. https://doi.org/10.3390/ ijgi4010199

Bechtel B, Demuzere M, Sismanidis P, Fenner D, Brousse O, Beck C, Van Coillie F, Conrad O, Keramitsoglou I, Middel A et al (2017) Quality of crowdsourced data on urban morphologythe human influence experiment (huminex). Urban Sci 1(2):15. https://doi.org/10.3390/urbansci1020015

Bechtel B, Demuzere M, Stewart ID (2020) A weighted accuracy measure for land cover mapping: Comment on johnson others. local climate zone (lcz) map accuracy assessments should account for land cover physical characteristics that affect the local thermal environment. Remote Sens 12(11):1769. https://doi.org/10.3390/ rs12111769

Beninde J, Veith M, Hochkirch A (2015) Biodiversity in cities needs space: A meta-analysis of factors determining intra-urban biodiversity variation. https://doi.org/10.1111/ele.12427

Breiman L (2001) Random forests, vol 45. https://doi.org/10.1023/ A: 1010933404324

Brousse O, Martilli A, Foley M, Mills G, Bechtel B (2016) Wudapt, an efficient land use producing data tool for mesoscale models? integration of urban lcz in wrf over madrid. Urban Clim 17:116134. https://doi.org/10.1016/j.uclim.2016.04.001

Brousse O, Georganos S, Demuzere M, Vanhuysse S, Wouters H, Wolff E, Linard C, van Lipzig NP, Dujardin S (2019) Using local climate zones in sub-saharan africa to tackle urban health issues. Urban Clim 27:227-242. https://doi.org/10.1016/j.uclim.2018.12. 004

Brousse O, Wouters H, Demuzere M, Thiery W, Van de Walle J, van Lipzig NP (2020) The local climate impact of an African city during clear-sky conditions-Implications of the recent urbanization in Kampala (Uganda). Int J Climatol 40:4586-4608. https://doi.org/10.1002/joc.6477

Ching J, Mills G, Bechtel B, See L, Feddema J, Wang X, Ren C, Brousse O, Martilli A, Neophytou M, Mouzourides P, Stewart I, Hanna A, Ng E, Foley M, Alexander P, Aliaga D, Niyogi D, Shreevastava A, Bhalachandran P, Masson V, Hidalgo J, Fung J, 
Andrade M, Baklanov A, Dai W, Milcinski G, Demuzere M, Brunsell N, Pesaresi M, Miao S, Mu Q, Chen F, Theeuwes N (2018) World urban database and access portal tools (WUDAPT), an urban weather, climate and environmental modeling infrastructure for the Anthropocene. Bull Am Meteorol Soc 99(9):1907-1924. https://doi.org/10.1175/BAMS-D-16-0236.1

Coccolo S, Kämpf J, Scartezzini JL, Pearlmutter D (2016) Outdoor human comfort and thermal stress: A comprehensive review on models and standards. https://doi.org/10.1016/j.uclim.2016.08. 004

De Colstoun ECB, Huang C, Wang P, Tilton JC, Phillips J, Niemczura S, Ling P, Wolfe R (2017) Documentation for the global man-made impervious surface (GMIS) dataset from landsat. NASA Socioeconomic Data and Applications Center (SEDAC): Palisades, USA. http://img.data.ac.cn/geores/M00/03/ 8D/n-JvD1pVvD6AGx1vAAjQnFzHcL8490.pdf

Dee DP, Uppala SM, Simmons A, Berrisford P, Poli P, Kobayashi S, Andrae U, Balmaseda M, Balsamo G, Bauer P et al (2011) The era-interim reanalysis: Configuration and performance of the data assimilation system. Q J Roy Meteorol Soc 137(656):553-597. https://doi.org/10.1002/qj.828

Demuzere M, Harshan S, Järvi L, Roth M, Grimmond CS, Masson V, Oleson KW, Velasco E, Wouters H (2017) Impact of urban canopy models and external parameters on the modelled urban energy balance in a tropical city. Q J Roy Meteorol Soc 143:1581-1596. https://doi.org/10.1002/qj.3028

Demuzere M, Bechtel B, Middel A, Mills G (2019a) Mapping europe into local climate zones. PLOS ONE 14(4):1-27. https://doi.org/ 10.1371/journal.pone.0214474

Demuzere M, Bechtel B, Mills G (2019b) Global transferability of local climate zone models. Urban Clim 27:46-63. https://doi.org/ 10.1016/j.uclim.2018.11.001

Demuzere M, Hankey S, Mills G, Zhang W, Lu T, Bechtel B (2020) Combining expert and crowd-sourced training data to map urban form and functions for the continental us. Sci Data 7(1):1-13. https://doi.org/10.1038/s41597-020-00605-z

Doms G, Förstner J, Heise E, Herzog H, Mironov D, Raschendorfer M, Reinhardt T, Ritter B, Schrodin R, Schulz JP et al (2011) A description of the nonhydrostatic regional cosmo model. part ii: Physical parameterization Deutscher Wetterdienst, Offenbach, Germany

Frumkin H (2002) Urban sprawl and public health. Publ Health Rep 117(3):201-217. https://doi.org/10.1093/phr/117.3.201

Gogh RV (1979) A note on the pretoria urban heat island of 15-16 june, 1977. S Afr Geogr J 61(1):29-34. https://doi.org/10.1080/ 03736245.1979.10559602

Gorelick N, Hancher M, Dixon M, Ilyushchenko S, Thau D, Moore R (2017) Google earth engine: Planetary-scale geospatial analysis for everyone. Remote Sens Env 202:18-27. https://doi.org/10. 1016/j.rse.2017.06.031, big Remotely Sensed Data: tools, applications and experiences

Hammerberg K, Brousse O, Martilli A, Mahdavi A (2018) Implications of employing detailed urban canopy parameters for mesoscale climate modelling: A comparison between WUDAPT and GIS databases over Vienna, Austria. Int J Climatol 38:e1241e1257. https://doi.org/10.1002/joc.5447

Hann J (1885) Ober den temperaturunterschied zwischen stadt und land. 6sterreichischen Gesellschaft fur Meteorologie Zeitschrift 20:457-462

Hemerijckx LM, Van Emelen S, Rymenants J, Davis J, Verburg PH, Lwasa S, Van Rompaey A (2020) Upscaling household survey data using remote sensing to map socioeconomic groups in kampala, uganda. Remote Sens 12(20):3468. https://doi.org/10.3390/ rs 12203468

Herold M, Roberts DA, Gardner ME, Dennison PE (2004) Spectrometry for urban area remote sensing-development and analysis of a spectral library from 350 to $2400 \mathrm{~nm}$. Remote Sens Environ 91(3):304-319. https://doi.org/10.1016/j.rse.2004.02.013

Howard L (1833) The climate of London: deduced from meteorological observations made in the metropolis and at various places around it, vol 3. Harvey and Darton, J. and A. Arch, Longman, Hatchard, S. Highley [and] R. Hunter

Jackson TL, Feddema JJ, Oleson KW, Bonan GB, Bauer JT (2010) Parameterization of urban characteristics for global climate modeling. Ann Assoc Am Geogr 100(4):848-865. https://doi.org/10. 1080/00045608.2010.497328

Jones PW (1999) First-and second-order conservative remapping schemes for grids in spherical coordinates. Monthly Weather Rev 127(9):2204-2210. https://doi.org/10.1175/1520-0493(1999) 127\%3C2204:FASOCR\%3E2.0.CO;2

Jonsson P, Bennet C, Eliasson I, Selin Lindgren E (2004) Suspended particulate matter and its relations to the urban climate in dar es salaam, tanzania. Atmos Environ 38(25):4175-4181. https://doi.org/10.1016/j.atmosenv.2004.04.021

Kamusoko C (2017) Importance of remote sensing and land change modeling for urbanization studies. Springer Singapore, Singapore, pp 3-10. https://doi.org/10.1007/978-981-10-3241-7_1

Kaspersen PS, Fensholt R, Drews M (2015) Using landsat vegetation indices to estimate impervious surface fractions for european cities. Remote Sens 7(6):8224-8249. https://doi.org/10.3390/ rs70608224

Kotthaus S, Smith TE, Wooster MJ, Grimmond C (2014) Derivation of an urban materials spectral library through emittance and reflectance spectroscopy. ISPRS J Photogramm Remote Sens 94:194-212. https://doi.org/10.1016/j.isprsjprs.2014.05.005

Loridan T, Grimmond C (2012) Multi-site evaluation of an urban land-surface model: intra-urban heterogeneity, seasonality and parameter complexity requirements. Q J Roy Meteorol Soc 138(665):1094-1113. https://doi.org/10.1002/qj.963

Louw W, Meyer J (1965) Near-surface nocturnal winter temperatures in pretoria. Notos 14:49-65

Martilli A (2014) An idealized study of city structure, urban climate, energy consumption, and air quality. Urban Clim 10:430-44. https://doi.org/10.1016/j.uclim.2014.03.003, iCUC8: The 8th International Conference on Urban Climate and the 10th Symposium on the Urban Environment

Mironov D, Raschendorfer M (2001) Evaluation of empirical parameters of the new $1 \mathrm{~m}$ surface-layer parameterization scheme. Tech. rep., Tech. rep., COSMO Tech. Rep. 1, 12 pp. http://www.cosmo-model.org/content/model/documentation/ techReports/docs/techReport01.pdf

Mironov D, Heise E, Kourzeneva E, Ritter B, Schneider N, Terzhevik A (2010) Implementation of the lake parameterisation scheme flake into the numerical weather prediction model cosmo. Boreal Environ Res Publ Board 15:218-230. https://helda.helsinki.fi/ bitstream/handle/10138/233087/ber15-2-218.pdf?sequence=1

Muller C, Chapman L, Johnston S, Kidd C, Illingworth S, Foody G, Overeem A, Leigh R (2015) Crowdsourcing for climate and atmospheric sciences: current status and future potential. https://doi.org/10.1002/joc. 4210

Muller CL, Chapman L, Grimmond CSB, Young DT, Cai X (2013) Sensors and the city: a review of urban meteorological networks. https://doi.org/10.1002/joc.3678

Nakamura K (1966) City temperature of nairobi. J Geogr (Chigaku Zasshi) 75(6):316-325. https://doi.org/10.5026/jgeography.75.6_316

Nasarudin NEM, Shafri HZM (2011) Development and utilizatino of urban spectral library for remote sensing of urban environment. J Urban Environ Eng 5(1):44-56. http://www.jstor.org/stable/ 26203355

Nawrotzki RJ, DeWaard J, Bakhtsiyarava M, Ha JT (2017) Climate shocks and rural-urban migration in Mexico: Exploring 
nonlinearities and thresholds. Clim Change 140(2):243-258. https://doi.org/10.1007/s10584-016-1849-0

Ndetto EL, Matzarakis A (2013) Basic analysis of climate and urban bioclimate of dar es salaam, tanzania. Theor Appl Climatol 114(1):213-226. https://doi.org/10.1007/s00704-012-0828-2

Ndetto EL, Matzarakis A (2015) Urban atmospheric environment and human biometeorological studies in dar es salaam, tanzania. Air Qual Atmos Health 8(2):175-191. https://doi.org/10.1007/ s11869-014-0261-z

Offerle B, Jonsson P, Eliasson I, Grimmond C (2005) Urban modification of the surface energy balance in the west african sahel: Ouagadougou, burkina faso. J Climate 18(19):3983-3995. https://doi.org/10.1175/JCLI3520.1

Oke TR, Mills G, Christen A, Voogt JA (2017) Urban climates. Cambridge University Press, Cambridge. https://doi.org/10.1017/ 9781139016476

Okoola R (1979) The Nairobi heat island. University of Nairobi

Okpara J (2002) A case study of urban heat island over akure city in Nigeria during the end of wet (october-november) season. J African Meteorol Soc 5(2):43-53

Panitz HJ, Dosio A, Büchner M, Lüthi D, Keuler K (2014) Cosmo-clm (cclm) climate simulations over cordex-africa domain: analysis of the era-interim driven simulations at 0.44 and 0.22 resolution. Clim Dyn 42(11-12):3015-3038. https://doi.org/10.1007/s00382013-1834-5

Ramon D, Allacker K, De Troyer F, Wouters H, van Lipzig NP (2020) Future heating and cooling degree days for Belgium under a high-end climate change scenario. Energ Buildings 216:109935. https://doi.org/10.1016/j.enbuild.2020.109935

Renou E (1868) Differences de temperature entre la ville et la campagne. Annuaire Socié,té Météorologie de France 3:83-97

Ritter B, Geleyn JF (1992) A comprehensive radiation scheme for numerical weather prediction models with potential applications in climate simulations. Monthly weather review 120(2):303-325

Rockel B, Will A, Hense A (2008) The regional climate model COSMO-CLM (CCLM). https://doi.org/10.1127/0941-2948/ 2008/0309

Roth M (2007) Review of urban climate research in (sub)tropical regions. Int J Climatol 27(14):1859-1873. https://doi.org/10.1002/joc.1591

Santamouris M, Cartalis C, Synnefa A, Kolokotsa D (2015) On the impact of urban heat island and global warming on the power demand and electricity consumption of buildings - a review. Energ Build 98:119-124. https://doi.org/10.1016/j.enbuild.2014. 09.052, renewable Energy Sources and Healthy Buildings

Schulz JP, Vogel G (2020) An improved representation of the land surface temperature including the effects of vegetation in the COSMO model. In: EGU general assembly conference abstracts, EGU general assembly conference abstracts, p 22029

Schulz JP, Vogel G, Becker C, Kothe S, Ahrens B (2015) Evaluation of the ground heat flux simulated by a multi-layer land surface scheme using high-quality observations at grass land and bare soil. In: EGU General assembly conference abstracts, EGU general assembly conference abstracts, p 6549

Scott AA, Misiani H, Okoth J, Jordan A, Gohlke J, Ouma G, Arrighi J, Zaitchik BF, Jjemba E, Verjee S, Waugh DW (2017) Temperature and heat in informal settlements in nairobi. PLOS ONE 12(11):117. https://doi.org/10.1371/journal.pone.0187300

Stewart ID (2011a) Redefining the urban heat island. PhD thesis, University of British Columbia. https://circle.ubc.ca/handle/2429/ 38069

Stewart ID (2011b) A systematic review and scientific critique of methodology in modern urban heat island literature. Int J Climatol 31(2):200-217. https://doi.org/10.1002/joc.2141
Stewart ID (2019) Why should urban heat island researchers study history? Urban Clim 30:100484. https://doi.org/10.1016/j.uclim. 2019.100484

Stewart ID, Oke TR (2012) Local climate zones for urban temperature studies. Bull Am Meteorol Soc 93(12):1879-1900. https://doi.org/10.1175/BAMS-D-11-00019.1

Thiery W, Martynov A, Darchambeau F, Descy JP, Plisnier PD, Sushama L, van Lipzig NPM (2014a) Understanding the performance of the flake model over two african great lakes. Geosci Model Dev 7(1):317-337. https://doi.org/10.5194/gmd-7317-2014

Thiery W, Stepanenko VM, Fang X, Jöhnk KD, Li Z, Martynov A, Perroud M, Subin ZM, Darchambeau F, Mironov D, van Lipzig NP (2014b) Lakemip kivu: evaluating the representation of a large, deep tropical lake by a set of one-dimensional lake models. Tellus A: Dyn Meteorol Oceanogr 66(1):21390. https://doi.org/10.3402/tellusa.v66.21390

Thiery W, Davin EL, Panitz HJ, Demuzere M, Lhermitte S, van Lipzig $\mathrm{N}$ (2015) The impact of the african great lakes on the regional climate. J Clim 28(10):4061-4085. https://doi.org/10.1175/JCLID-14-00565.1

Tiedtke M (1989) A comprehensive mass flux scheme for cumulus parameterization in large-scale models. Monthly Weather Rev 117(8):1779-1800. https://doi.org/10.1175/1520-0493(1989) $117<1779$ :ACMFSF $>2.0$.CO;2

Vandamme S, Demuzere M, Verdonck ML, Zhang Z, Van Coillie F (2019) Revealing kunming's (china) historical urban planning policies through local climate zones. Remote Sens 11(14):1731. https://doi.org/10.3390/rs11141731

van de Giesen N, Hut R, Selker J (2014) The trans-african hydrometeorological observatory (tahmo). WIREs Water 1(4):341-348. https://doi.org/10.1002/wat2.1034

Van de Walle J, Brousse O, Arnalsteen L, Byarugaba D, Ddumba D, Demuzere M, Lwasa S, Nsangi G, Sseviiri H, Thiery W, Vanhaeren R, Wouters H, van Lipzig N (2020a) Climate-relevant urban canopy parameter measurements in kampala, uganda. https://doi.org/10.5281/zenodo.3930199

Van de Walle J, Thiery W, Brousse O, Souverijns N, Demuzere M, van Lipzig NP (2020b) A convection-permitting model for the lake victoria basin: evaluation and insight into the mesoscale versus synoptic atmospheric dynamics. Clim Dynam 54(3):1779-1799. https://doi.org/10.1007/s00382-019-05088-2

Varentsov M, Samsonov T, Demuzere M (2020) Impact of urban canopy parameters on a megacity's modelled thermal environment. Atmosphere 11(12):1349. https://doi.org/10.3390/atmos11121349

Verdonck ML, Van Coillie F, De Wulf R, Okujeni A, Van Der Linden S, Demuzere M, Hooyberghs H (2017) Thermal evaluation of the local climate zone scheme in Belgium. In: 2017 Joint urban remote sensing event, JURSE 2017, https://doi.org/10.1109/JURSE.2017.7924556

Verdonck M, Demuzere M, Bechtel B, Beck C, Brousse O, Droste A, Fenner D, Leconte F, Van Coillie F (2019) The human influence experiment (part 2): Guidelines for improved mapping of local climate zones using a supervised classification. Urban Sci 3(1):27. https://doi.org/10.3390/urbansci3010027

Vermeiren K, Van Rompaey A, Loopmans M, Serwajja E, Mukwaya P (2012) Urban growth of kampala, uganda: Pattern analysis and scenario development. Landsc Urban Plan 106(2):199-206. https://doi.org/10.1016/j.landurbplan.2012.03.006

Wan Z (2007) Collection-5 modis land surface temperature products users' guide. icess. Citeseer https://landweb.modaps.eosdis. nasa.gov/QA_WWW/forPage/user_guide/061/MOD11_C61_ UsersGuide_revSudipta_revPete_Final.pdf 
Wan Z, Zhang Y, Zhang Q, Li ZL (2004) Quality assessment and validation of the modis global land surface temperature. Int J Remote Sens 25(1):261-274. https://doi.org/10.1080/ 0143116031000116417

Weng Q (2012) Remote sensing of impervious surfaces in the urban areas: Requirements, methods, and trends. Remote Sens Env 117:34-49. https://doi.org/10.1016/j.rse.2011.02.030, remote Sensing of Urban Environments

Wong MMF, Fung JCH, Ching J, Yeung PPS, Tse JWP, Ren C, Wang R, Cai M (2019) Evaluation of uwrf performance and modeling guidance based on wudapt and nudapt ucp datasets for hong kong. Urban Clim 28:100460. https://doi.org/10.1016/j.uclim.2019.100460

Wouters H, Demuzere M, Blahak U, Fortuniak K, Maiheu B, Camps J, Tielemans D, van Lipzig NPM (2016) The efficient urban canopy dependency parametrization (sury) v1.0 for atmospheric modelling: description and application with the cosmo-clm model for a belgian summer. Geosci Model Dev 9(9):3027-3054. https://doi.org/10.5194/gmd-9-3027-2016
Wouters H, De Ridder K, Poelmans L, Willems P, Brouwers J, Hosseinzadehtalaei P, Tabari H, Vanden Broucke S, van Lipzig NPM, Demuzere M (2017) Heat stress increase under climate change twice as large in cities as in rural areas: A study for a densely populated midlatitude maritime region. Geophys Res Lett 44(17):8997-9007. https://doi.org/10.1002/2017GL074889

Zhang Q, Li B, Thau D, Moore R (2015) Building a better urban picture: Combining day and night remote sensing imagery. Remote Sens 7(9):11887-11913. https://doi.org/10.3390/rs70911887

Zonato A, Martilli A, Di Sabatino S, Zardi D, Giovannini L (2020) Evaluating the performance of a novel wudapt averaging technique to define urban morphology with mesoscale models. Urban Clim. 31:100584. https://doi.org/10.1016/j.uclim.2020.100584

Publisher's note Springer Nature remains neutral with regard to jurisdictional claims in published maps and institutional affiliations.

\title{
Affiliations
}

Jonas Van de Walle ${ }^{1}$ (D) . Oscar Brousse ${ }^{1,2} \cdot$ Lien Arnalsteen $^{3}$. Disan Byarugaba ${ }^{3}$. Daniel S. Ddumba ${ }^{3}$. Matthias Demuzere $^{4,5}$ - Shuaib Lwasa ${ }^{3}$. Gloria Nsangi ${ }^{6} \cdot$ Hakimu Sseviiri $^{3}$ - Wim Thiery ${ }^{7} \cdot$ Roxanne Vanhaeren $^{1}$. Hendrik Wouters ${ }^{5,8} \cdot$ Nicole P.M. van Lipzig ${ }^{1}$

\author{
KU Leuven, Celestijnenlaan 200e, Leuven, Belgium \\ University College London, London, UK \\ Makerere University, Kampala, Uganda \\ Ruhr-University Bochum, Bochum, Germany \\ Ghent University, Ghent, Belgium \\ University of Oklahoma, Norman, USA \\ Vrije Universiteit Brussel, Brussels, Belgium \\ Flemish Institute for Technological Research, Mol, Belgium
}

